Juan Jorge Faundes, Derecho fundamental a la identidad cultural de los pueblos indígenas: un nuevo paradigma en la defensa penal indígena en Chile frente al Estado de Derecho hegemónico, Izquierdas, 45, febrero 2019:51-78

\title{
Derecho fundamental a la identidad cultural de los pueblos indígenas: un nuevo paradigma en la defensa penal indígena en Chile frente al Estado de Derecho hegemónico
}

\author{
Fundamental right to the cultural identity of indigenous peoples: a new paradigm \\ in indigenous criminal defense in Chile in the face of the hegemonic Rule of Law
}

\author{
Juan Jorge Faundes Peñafiel*
}

\begin{abstract}
Resumen: Sostenemos que el reconocimiento del derecho fundamental a la identidad cultural de los pueblos indígenas tiene un impacto jurídico potencialmente emancipatorio que introduce una fractura en la concepción hegemónica del Estado de Derecho, en especial, para la defensa penal de personas indígenas. Para ello, planteamos una fundamentación normativa evolutiva de los derechos humanaos y una propuesta teórica crítica intercultural que contrastamos con evidencia jurisprudencial.
\end{abstract}

Palabras clave: derecho identidad cultural, pueblos indígenas, defensa penal

Abstract: We argue that the recognition of the fundamental right to the cultural identity of indigenous peoples has a legal impact and potentially emancipatory scope that introduces a fracture in the hegemonic conception of the Rule of Law, especially for the criminal defense of indigenous persons. To this end, we propose an evolutionary normative foundation of human rights and an intercultural critical theoretical proposal that we contrast with jurisprudential evidence.

Key words: cultural identity right, indigenous peoples, criminal defense

Recibido: 2 marzo 2018 Aceptado: 28 mayo 2018

\footnotetext{
* Chileno. Doctor en procesos sociales y políticos en América Latina, mención Ciencia Política, por el PROSPAL de la Universidad ARCIS de Chile, con una tesis evaluada con excelencia sobre el reconocimiento de los pueblos indígenas en América Latina, que aborda el caso del Pueblo Mapuche. Abogado y Licenciado en Ciencias Jurídicas y Sociales de la U. Austral de Chile. Docente investigador de la Universidad Autónoma de Chile, Sede Temuco. Junto a sus labores académicas ha patrocinado casos emblemáticos en materia de Pueblos Indígenas en Chile y ante la CIDH. Este trabajo forma parte del Proyecto Fondecyt Iniciación N ${ }^{\circ} 11161079$, "El derecho fundamental a la identidad cultural de los pueblos indígenas en Chile, debates y problemas a la luz de la jurisprudencia conforme al Convenio N 169 de la OIT” (2016-2019). Además, participa de la tesis Doctoral del mismo autor en curso en el Doctorado en Derecho de la Universidad de Sevilla sobre El derecho fundamental a la identidad cultural de los pueblos indígenas en la Cte.IDH y su "diálogo" con el TEDH. juanjorgef@gmail.com
} 


\section{Introducción}

El ejercicio y defensa de los derechos de los pueblos indígenas, bajo los sistemas de administración de justicia estatales en América Latina, presentan una disputa discursiva en desequilibrio de poder. En especial, se trata de una interacción social y normativa que se lleva a cabo sobre la base de las reglas y los referentes de sentido de una sola de las partes -el Estado nación-. El Estado mantiene el control del sistema normativo bajo el marco de comprensión de los miembros de la cultura dominante, subordinando o incluso negando la cultura de pueblos originarios cuya existencia es previa a dicho Estado. Sin embargo, como veremos, el derecho fundamental a la identidad cultural viene a fisurar este sistema.

La subordinación normativa indicada incide en el escenario de conflicto social, político e interétnico en el que se desenvuelven ancestralmente y luchan por su reconocimiento los pueblos indígenas, porque los miembros de dichos pueblos cuando ejercen derechos de naturaleza colectiva o cuando realizan acciones en reivindicación de sus derechos conculcados, ven sometida su conducta a examen judicial por parte del mismo Estado que ha establecido las reglas impugnadas. Por ejemplo, en el caso de Chile, hablaremos del ejercicio de acciones penales contra miembros del Pueblo Mapuche que reivindican su territorio ancestral, que en lengua Mapuche se conoce como Wall Mapu y que la sociedad chilena hegemónica "renombró” llamándolo Región de la Araucanía.

En relación con esta cuestión, coincidimos con quienes postulan que para hablar de justicia, primero y en el plano estructural, se requiere individuos y grupos con la capacidad de ser sujetos políticos en la disputa democrática, para -solo luego de ello- poder intervenir como "parte" en la definición contextual específica de la Justicia, tanto en el sentido de la distribución, como en su sentido particular "judicial-procesal". Por ello, la cuestión de la Justicia siempre supondrá el problema del poder de quienes "son" pero que no pueden "decir" acerca de la distribución de las partes, porque "las partes ya están dadas"2.

Asimismo, desde la perspectiva de los sistemas normativos en conflicto, hasta ahora, la vía judicial no ha sido adecuada para el abordaje de controversias como la emergencia de los pueblos indígenas, en tanto sujetos políticos frente al Estado. En especial, según hemos sostenido en otros trabajos, una transformación estructural capaz de dar cuenta de este problema debiera enmarcarse en un escenario político constituyente y efectivamente intercultural que permita a los pueblos indígenas, entre otras cuestiones centrales, tener derecho a su propia jurisdicción, como base de un sistema de justicia estatal plurinacional receptor de un auténtico "pluralismo jurídico".

Sin embargo, por sobre las prevenciones de los párrafos anteriores, aquí vamos a desarrollar una tesis que, sin desestimar la lucha social y política por un nuevo Estado intercultural, revisa

\footnotetext{
${ }^{1}$ Mariman, Pablo, "Los mapuche antes de la conquista militar chileno-argentina”, en P. Mariman, S. Caniuqueo, S. Millalen, R. Levil, ï...Escucha, winka...!! Cuatro ensayos de historia nacional mapuche y un epílogo sobre el futuro, 53-127, Santiago, LOM Ediciones, 2006, 54.

2 Rancière, Jack, El desacuerdo. Politica y Filosofía, 1996, B. Aires, Nueva Visión, 130. Forst, Rainer, Justificación y crítica. Perspectivas de una teoría crítica de la política, B.Aires, kats Editores, 2014, 44-45.

${ }^{3}$ Faundes, Juan Jorge, "Recomprensión intercultural de los derechos humanos. Apuntes para el reconocimiento de los pueblos indígenas en América Latina”, Justiça do Direito, v.29, Nº1, 2015, 109.
} 
los efectos desestructurantes que arroja la recepción del derecho fundamental a la identidad cultural de los pueblos indígenas dentro del propio sistema legal, especialmente el penal. Todo, conforme el análisis teórico y la evidencia recogida en relación al mismo ejercicio de este derecho fundamental integrado en la defensa penal de imputados indígenas. Este cambio radica, aunque sea en una etapa inicial y todavía difusa, en que, con la emergencia del nuevo derecho, ya no se tratará de la "subsunción" del derecho indígena al derecho estatal, sino de la "distorsión" que genera este derecho fundamental al "escurrirse" en el sistema normativo del Estado nación.

En primer término, sin entrar en la revisión de la conducta en sí de sujetos indígenas perseguidos penalmente, podemos afirmar que un proceso que se ventile al margen del marco de comprensión de sentidos - cultura- en que ocurren los hechos de relevancia jurídica, será un "juicio injusto". Segundo, también podemos sostener que un procedimiento judicial que no permita el efectivo ejercicio del derecho fundamental a la identidad cultural constituye una herramienta de dominación y disciplinamiento cultural ${ }^{4}$. Al pretender que los miembros de pueblos indígenas actúen bajo los códigos del sistema de justicia de la sociedad hegemónica, los imputados tenderán a renunciar a su marco identitario cultural para buscar pragmáticamente posibilidades de defensa (por ejemplo, alegando desconocimiento de la norma penal o un "error de comprensión" de dicha norma).

Ahora bien -como hemos dicho-, más allá de las premisas recién planteadas en torno al marco normativo, en un giro que consideramos paradigmático, aunque en etapa recién emergente, el Derecho Internacional de los Derechos Humanos ha reconocido el "Derecho a la Identidad Cultural" de los pueblos indígenas como derecho fundamental, de naturaleza colectiva, propio de las sociedades pluralistas y democráticas ${ }^{5}$. Este mandato arroja diversos problemas frente al principio imperante de igualdad democrático liberal, lo que hace necesario desarrollar mecanismos de articulación efectivamente intercultural con el objeto de abordar tales problemas. Luego, los estados latinoamericanos deben adecuar su ordenamiento jurídico para dar concreción al derecho fundamental a la identidad cultural. Estas transformaciones, idealmente, se debieran iniciar por reformas constitucionales y luego conducirse por vía legislativa. Sin embargo, no ha sido esa la praxis especialmente en el caso chileno que estudiamos, porque la principal fuente de recepción del derecho fundamental a la identidad cultural ha sido la jurisprudencia. En este sentido, se trata de una nueva hermenéutica jurídica evolutiva de los derechos humanos que acompaña las luchas por el reconocimiento de los pueblos indígenas y sus derechos.

La idea de una hermenéutica de los derechos humanos conecta dos sentidos. Tanto refiere al "Arte de interpretar textos", como corresponde a la "teoría de la verdad y el método que expresa la universalización del fenómeno interpretativo desde la concreta y personal historicidad" ". En el primer enfoque, jurídico, la hermenéutica "es el sinónimo más común de interpretación"”. Luego, para el Derecho interpretar es la actividad dirigida a determinar el

4 Salgado, Manuel “Cómo la práctica procesal anula los derechos indígenas”, en Derecho y Pueblo Mapuche. Aportes para la discusión, 51-67. Santiago: Centro Derechos Humanos UDP, 2015, 57-58.

5 Cte.I.D.H, "Sarayaku vs. Ecuador", 2012.

${ }^{6}$ RAE, Diccionario de la lengua española: "hermenéutico, ca", 2018.

7 Preciado, Hugo, Interpretación de los Derechos Humanos y los Derechos Fundamentales, Pamplona, Tomson Reuters ARANZANDI, 2016, 54. 
sentido y alcance de las normas, es el ejercicio necesario para la aplicación de la norma a un caso concreto $^{8}$. Busca establecer los valores culturales (morales) subyacentes en la norma que la justifican, propios de una realidad social en un momento histórico determinado ${ }^{9}$. Desde el segundo enfoque, filosófico, - como explica Salas- la hermenéutica permite revelar y relevar "un pensar enraizado en las tradiciones y mitos indígenas" que implica la re-construcción crítica de los discursos "para dar cuenta de los cambios históricos de la normatividad cultural". Así vista, la hermenéutica contiene una "normatividad dinámica" enlazada a los contextos, en tanto "reformulación ética del conflicto teórico entre tradición y modernidad"10.

Articulando estos sentidos, nuestra propuesta, por una parte, jurídicamente, sigue una interpretación evolutiva de los derechos humanos, en tanto una interpretación extensiva de los tratados internacionales de derechos humanos, como "instrumentos vivos" que deben adaptarse a los tiempos y los contextos ${ }^{11}$. Y, por otra, se fundamenta en el enfoque hermenéutico de la Filosofía Intercultural Latinoamericana ${ }^{12}$, de la lucha por un reconocimiento efectivamente intercultural que concretice el derecho fundamental a la identidad cultural de los pueblos indígenas.

En relación a la estructura de este trabajo, primero, presentamos el nuevo enfoque que surge en América Latina para el derecho fundamental a la identidad cultural de los pueblos indígenas a partir de la jurisprudencia de la Corte Interamericana de Derechos Humanos (Cte.I.D.H.). Al respecto, debemos advertir que no hacemos aquí una revisión de las discusiones que extensamente se han planteado en la Antropología sobre los conceptos de identidad y cultura, su relación y sus diferencias ${ }^{13}$. Pero sí, en síntesis, hemos acogido la idea del "reconocimiento intercultural" y del "descentramiento intercultural" ", como puntos de partida (no del todo resueltos) para poder plantear una concepción intercultural de los derechos humanos sustentada en el derecho fundamental a la identidad cultural ${ }^{15}$.

A continuación, entramos al campo normativo, primero, con un acercamiento al derecho a la identidad cultural desde el Derecho Internacional de los Derechos Humanos. Después desarrollamos una fundamentación que enlaza el derecho fundamental a la identidad cultural con las normas de la Constitución Chilena, en una interpretación extensiva que llega a trastocar las bases mismas con que se concibió este instrumento (1973-1980).

\footnotetext{
${ }^{8}$ Squella, Agustín, Introducción al Derecho, Santiago, Ed. Jurídica de Chile, 2000, 377-380.

${ }^{9}$ Rodríguez, Pablo, Teoría de la Interpretación Jurídica, Santiago, Ediimpres Ltda., 1990, 30-32.

${ }^{10}$ Salas, Ricardo, Ética Intercultural. (Re)lecturas del Pensamiento latinoamericano, Santiago, Ediciones UCSH, 2003, $92-$ 93.

${ }^{11}$ Cte.I.D.H., "Sarayaku vs. Ecuador”, 2012.

12 Salas, Ricardo, op. cit:; Fornet-Betancourt, Raúl, Supuestos filosóficos del diálogo intercultural, 1998; La Filosofía Intercultural y la dinámica del reconocimiento, Temuco, Ediciones Universidad Católica de Temuco, 2011; Kusch, Rodolfo, América profunda, B. Aires, Hachette, 1962, 92-93.

${ }^{13}$ Entre otros: Grimson, Alejandro, "Los Límites de la cultura. Crítica de las teorías de la identidad", B. Aires, S. XXI Eds., 2011; Vergara, Jorge, et al, "Tramas y laberintos: sociología e identidad cultural latinoamericana", Atenea, 2012, No 15, 13.

14 Faundes, Juan Jorge, "Honneth y la demanda por reconocimiento intercultural de los pueblos indígenas", Perfiles Latinoamericanos, $\mathrm{N}^{\circ}$ 49, junio, 303-323, 2017a; "Derechos humanos y el reconocimiento de la identidad cultural de los pueblos indígenas en América Latina, en la perspectiva crítica del descentramiento intercultural", en Jorge Olvera, et al (coords.), La construcción de ciudadanías alternativas y vida política de los pueblos originarios de América Latina, México, UAEM, Porrúa, 2017b.

${ }^{15}$ Faundes, Juan Jorge, 2015, op. cit..
} 
Lugo de establecer su fundamentación jurídica, abordamos el peritaje antropológico, como medio que tiene la potencia de introducir y de hacer efectivo el derecho fundamental a la identidad cultural en la defensa penal de imputados indígenas. Conjuntamente, planteamos algunos problemas que en el campo teórico nos conducirán a lo que se ha denominado el "conflicto cultural" y la tensión que se presenta entre el derecho fundamental a la identidad cultural y el principio de igualdad democrático. Finalmente, para el análisis contextual de estos problemas, revisamos la evidencia jurisprudencial en las diversas materias en las que se puede presentar la defensa penal cultural.

Conforme lo descrito, sostendremos que el derecho fundamental a la identidad cultural justifica normativamente el derecho a hacer valer la propia cultura en el marco de los procesos judiciales. En especial, contiene el derecho a que las conductas que puedan a ser de relevancia penal, sean revisadas y ponderadas por los tribunales en el contexto cultural -bajo el sistema de principios y valores- en que aquella acción o interacción ocurrió o tuvo su origen. Este cambio, tanto visibiliza la necesidad de comprender y valorar las diferencias socioculturales de los pueblos indígenas y sus miembros ante la sociedad mayoritaria, como, particularmente, tiene la potencia contrahegemónica de desencadenar una transformación de la concepción del Derecho que se venía sosteniendo desde el paradigma del Estado nación y que se ha presentado como "Estado de Derecho",

\section{Antecedentes generales sobre el derecho a la identidad cultural}

Conceptualmente la identidad cultural se ha definido como el conjunto de referencias de tipo cultural mediante las cuales "una persona o un grupo se define, se manifiesta y desea ser reconocido" $"$. Comprende dos categorías enlazadas, la identidad y la cultura. Entonces el derecho a la identidad cultural reúne, a su vez, dos derechos: el derecho a la identidad y el derecho a la cultura. Así, por una parte, el derecho a la identidad refiere al amparo del sentido de pertenencia que un individuo tiene respecto de una determinada cultura ${ }^{18}$. Su derecho a que se respete su proyección en la vida social, tal como es en su contexto cultural ${ }^{19}$. Y, por otra, el derecho a la cultura apunta a la protección de dicha cultura -en sí-.

Ahora bien, para estos efectos, no suponemos una concepción integrista cultural, sino que acogemos la necesidad de redefinir la noción de cultura, como una trama de sentidos y significados transmitidos por símbolos, mitos, dichos, relatos, prácticas y reconstrucciones que expresan una comprensión y reconstrucción del sentido de la totalidad de la existencia y de los sujetos entre sí, que se constituye en la dialéctica entre autocomprensión de sí mismo y heterocomprensión ${ }^{20}$. En consecuencia, entendemos la cultura "abierta y dislocada", incapaz de

16 Recogemos la distinción entre "Estado de Derecho formal" y "Estado de Derecho material", descrita simbólicamente por Luis Tapia bajo la expresión "El estado de derecho como tiranía". Tapia, Luis, El estado de derecho como tirania, La Paz, CIDES, Autodeterminación, 2011.

${ }^{17}$ Ruiz Chiriboga, Oswaldo, "El derecho a la identidad cultural de los pueblos indígenas y las minorías nacionales: una mirada desde el sistema interamericano", Revista Internacional de Derechos Humanos, Vol. N5, año 3, 2006, 4369.

${ }^{18}$ Grimson, Alejandro, “Culture and identity: two different notions”, Social Identities, v.16 N¹, Jan. 2010, 63-79.

${ }_{19}$ Del Carpio Rodríguez, Columba, Pluralismo Jurídico, derecho bumano a la identidad cultural y globalización, Navarra, Editorial Aranzadi SA, 2014, 48-49.

${ }^{20}$ Salas, 2003, op. cit., 54-55. 
la determinación total de todos sus elementos, como una estructura permanentemente amenazada que no se entiende como universo único de sentido, sino descentrada, dinámica, siempre en relación y tensión frente a la emergencia y contingencia de pluralidad de centros culturales, diversa externa (otras culturas) e intraculturalmente ${ }^{21}$. Vista así, la cultura configura un núcleo "semiótico fundamental" que comprende "los valores, las normas, las representaciones, las relaciones expresivas y simbólicas" en que la cultura (las culturas) se muestra(n) como conjunto de sistemas y sub sistemas normativos, de representación, de expresión y de acción ${ }^{22}$. Y, jurídicamente, la Declaración Universal de la Unesco sobre la Identidad Cultural del año 2001 define cultura como "el conjunto de los rasgos distintivos espirituales y materiales, intelectuales y afectivos que caracterizan a una sociedad o a un grupo social" que comprende: los modos de vida, las maneras de vivir juntos, los sistemas de valores, las tradiciones y creencias, las artes y las letras.

Ahora bien, sin perjuicio de la composición dual del derecho fundamental a la identidad cultural, se ha llegado a conceptualizar como una sola categoría normativa y, para el caso latinoamericano, se ha reconocido especialmente a los pueblos indígenas. Desde esta perspectiva, podemos describir el derecho a la identidad cultural como:

El Derecho de todo colectivo étnico-cultural y de sus integrantes a conservar su propia cultura, su patrimonio cultural tangible o intangible, su memoria histórica y su presente y a ser reconocidos como diferente en sus relaciones con otros grupos de la sociedad. Comprende el derecho a que se respeten sus conocimientos, creencias, artes, moral, religión, normas y prácticas; y el derecho de sus miembros a pertenecer a una cultura, a no ser forzado a pertenecer a una cultura diferente o a no ser asimilado por aquella ${ }^{23}$.

De este enfoque se desprenden dos dimensiones del mismo derecho a la identidad cultural, la dimensión individual y la colectiva: la individual o indirecta que ampara al individuo y su identidad en la comunidad; y una directa que protege a la Comunidad como sujeto de derecho $^{24}$. La segunda será central para el caso de los pueblos indígenas en que se centran nuestras reflexiones, considerando que la Cte.I.D.H declaró expresamente la naturaleza colectiva del derecho fundamental a la identidad cultural.

En esta línea, por una parte, la identidad cultural, como objeto de protección jurídica, no es rígida, ya que cambia con el transcurso del tiempo, y se resignifica, en un proceso dinámico y en constante desarrollo, debido a su génesis comunitaria. Y, por otra, en el derecho a la identidad cultural subyace el interés normativo (emancipatorio y descolonizante) de "revalorizar las memorias de culturas hoy marginalizadas y amenazadas, pero que mantienen vivo el sentido profundo de sus tradiciones", precisamente porque ellas continúan siendo

${ }^{21}$ Claros, Luis y Viaña, Jorge, "La interculturalidad como lucha contrahegemónica. Fundamentos no relativistas para una crítica de la de la cultura”, en J. Viaña, et al, Interculturalidad crítica y descolonización Fundamentos para el debate, 81-147, La Paz, Convenio Andrés Bello, 117-118.

22 Salas, 2003, op. cit., 56.

${ }_{23}$ Síntesis desde: Del Carpio Rodríguez, op. cit. 48-49. Ruiz Chiriboga, Oswaldo, 2006, op. cit. 43-69. Fornet Betancourt, Raúl. "Tareas y propuestas de la filosofía intercultural, Sobre el concepto de identidad", Concordia Reibe Monographien Band 49, 2009a, 47-54.

${ }^{24}$ Corte Constitucional de Colombia, Sentencia T-778/05. Ruiz Chiriboga, Oswaldo, 2006, op. cit., 43-69; Del Real, Alberto, El derecho a la identidad cultural, Pamplona, Editorial Aranzadi S.A., 2014; 
fuente de estas culturas tradicionales insertas en las sociedades actuales ${ }^{25}$.

\section{Derecho internacional de los derechos humanos y el derecho a la identidad cultural}

La emergencia del derecho a la identidad cultural ha sido fruto de la profundización de los estándares de protección de las minorías culturales (principalmente étnicas y religiosas) en el Derecho Internacional, cuyo caso más avanzado es el de la Cte.I.D.H que reconoció este derecho, con carácter de fundamental, a los pueblos indígenas.

Sin extendernos en este trabajo, es necesario explicar brevemente que cuando la Cte.I.D.H. atribuye el carácter de derecho fundamental al derecho a la identidad cultural, lo incorpora al denominado bloque constitucional de derechos fundamentales. La consecuencia de este estatus normativo es el de pasar a constituir una norma imperativa para el Estado que opera como un límite para el ejercicio de la soberanía por parte de éste ${ }^{26}$. Con todo, para el caso de Chile, el derecho fundamental a la identidad cultural de los pueblos indígenas, conforme la interpretación vinculante que la Cte.I.D.H. hace de la Convención Americana de Derechos Humanos y a la luz del artículo 5 de la Constitución, se incorpora como un derecho implícito ${ }^{27}$, fruto de la hermenéutica evolutiva de los derechos humanos, ya que ni el texto literal de la Convención Americana referida, ni el de la Constitución de 1980 lo consideran.

Los principales instrumentos internacionales de derechos humanos a partir de los cuales se ha ido dando desarrollo progresivo a este derecho, vinculando evolutivamente la cultura con el derecho que la ampara, son la Declaración Universal de Derechos Humanos que dispone que toda persona tiene derecho a obtener "la satisfacción de los derechos económicos, sociales y culturales, indispensables a su dignidad y al libre desarrollo de su personalidad" (art. 22) y el derecho a "participar libremente en la vida cultural de la comunidad" (art. 27.1). Asimismo, el Pacto Internacional de Derechos Económicos, Sociales y Culturales (PIDESC), señala que todos los pueblos tienen el derecho de libre determinación y a definir su "desarrollo económico, social y cultural" (art. 1). El Pacto Internacional de Derechos Civiles y Políticos (PIDCP) asegura el derecho a las minorías étnicas, religiosas o lingüísticas a disfrutar colectivamente "de su propia cultura, a profesar y practicar su propia religión y a emplear su propio idioma" (art. 27). Por último, la Convención para la salvaguardia del patrimonio cultural inmaterial (2003) busca proteger el "patrimonio cultural inmaterial de las comunidades, grupos e individuos..." (art.1.a y b.).

Dentro de los instrumentos específicos referentes a los pueblos indígenas encontramos la Declaración de las Naciones Unidas sobre los Derechos de los pueblos Indígenas (DNUDPI)

\footnotetext{
${ }^{25}$ Fornet Betancourt, Raúl, 2009a, Idem.

26 Nogueira, Humberto, "El bloque constitucional de derechos: La confluencia del derecho internacional y del derecho constitucional en el aseguramiento y garantía de los derechos fundamentales en América Latina. Trigésimo séptimas Jornadas de Derecho Público", 1997. Faundes, Juan Jorge, "Derechos fundamentales y derechos humanos", en, M. Álvarez Ledesma y R. Cippitani (coords.), Diccionario Analítico de Derechos Humanos e Integración Juridica. Roma-Perugia-México: ISEG, 2013, 181-184.

27 Bidart Campos, Germán, "Los derechos «no enumerados» en su relación con el derecho constitucional y el derecho internacional", en Méndez Silva, Derecho internacional de los derechos bumanos: memoria del VII Congreso iberoamericano de derecho constitucional, B. Aires- México, IIJ, 2002, 103-113.
} 
y el Convenio 169 OIT sobre Pueblos Indígenas y Tribales en Países Independientes (Convenio 169). La DNUDPI recoge y protege diversas expresiones y alcances del derecho a la identidad cultural. Por ejemplo, asegura el derecho a la identidad como un derecho humano de naturaleza colectiva, expresando que la identidad se forja en el sentido de pertenencia que se tiene a un grupo humano, del que como individuo se siente parte y que se sustenta en el comportamiento de un grupo o comunidad humana ${ }^{28}$; que el derecho a la identidad cultural de los pueblos y los individuos indígenas comprende "el derecho a pertenecer a una comunidad o nación indígena, de conformidad con las tradiciones y costumbres de la comunidad o nación de que se trate" (art. 9); y el derecho a mantener, proteger y desarrollar las manifestaciones pasadas, presentes y futuras de sus culturas, como lugares arqueológicos e históricos, objetos, diseños, ceremonias, tecnologías, artes visuales e interpretativas y literaturas" (art. 11.1).

Por su parte, el Convenio 169 OIT fundamenta y protege el derecho a la identidad cultural de los pueblos indígenas, sostenido en la obligación de garantizar su integridad (art. 2.1) y de promover "la plena efectividad de los derechos sociales, económicos y culturales de esos pueblos, respetando su identidad social y cultural, sus costumbres y tradiciones, y sus instituciones (art. 2.2.b)". Paralelamente, la Cte. I.D.H. ha señalado que:

...la cultura de los pueblos indígenas corresponde a una forma de vida particular de ser, ver y actuar en el mundo, constituida a partir de su estrecha relación con sus tierras tradicionales y recursos naturales, no solo por ser estos su principal medio de subsistencia, sino además, porque constituyen un elemento integrante de su cosmovisión, religiosidad y por ende de su identidad cultural ${ }^{29}$.

Como enunciamos, en el caso "Sarayaku contra Ecuador", dijo que el derecho a la identidad cultural es un derecho fundamental y de naturaleza colectiva de las comunidades indígenas, que debe ser respetado en una sociedad multicultural, pluralista y democrática. A ello agregó que es "vía de interpretación transversal para concebir, respetar y garantizar el goce y ejercicio de los derechos humanos de los pueblos y comunidades indígenas protegidos por la Convención y por los ordenamientos jurídicos internos"30. Y, recientemente, en el caso "Sukuro versus Brasil”, asentó que: “...deberá garantizarle a los miembros de la Comunidad que puedan continuar viviendo su modo de vida tradicional, conforme a su identidad cultural, estructura social, sistema económico, costumbres, creencias y tradiciones distintivas"31.

\section{Nuevo enfoque emancipatorio para el derecho fundamental a la identidad cultural}

Sobre las bases normativas precedentes, el derecho fundamental a la identidad cultural de los pueblos indígenas opera como nuevo paradigma emancipatorio dentro del ordenamiento

\footnotetext{
28 Porma, Carolina, "El reconocimiento al derecho a la identidad cultural de los pueblos indígenas, en la jurisprudencia de los tribunales chilenos", Tesis para optar al grado de Magister en Derecho Público, Facultad de Derecho de la Universidad Autónoma de Temuco, Temuco, 2017, Proyecto Fondecyt N 11161079, 11.

${ }^{29}$ Cte.I.D.H., "Sawhoyamaxa vs. Paraguay", 2006.

${ }^{30}$ Cte.I.D.H., "Sarayaku vs. Ecuador", 2012.

${ }^{31}$ Cte.I.D.H., "Sukuro vs. Brasil”, 2018.
} 
jurídico positivo hegemónico ${ }^{32}$, lo que supone cuestiones por despejar, en especial respecto de la determinación del contenido de este derecho emergente. Por ejemplo, entre otros aspectos, al reconocerse el derecho a la identidad cultural en los ordenamientos internos, en general, se ha circunscrito a las potestades vinculadas a la administración de justicia y resolución de conflictos $^{33}$, pero también comprende otros ámbitos de la cultura y cosmovisión de los pueblos indígenas, tales como la participación y formas de organización tradicional, la consulta y los derechos territoriales.

En el Derecho Internacional y comparado, el derecho a la identidad cultural ha logrado un importante desarrollo progresivo, pero con mayor certeza ya se ha configurado su titularidad respecto a los pueblos indígenas de las sociedades latinoamericanas. Ello, arrojará diversos problemas para los estados nación y sus sistemas jurídicos monistas, especialmente, en los casos más complejos, como el de Chile, que no reconoce a los pueblos indígenas en el texto de su Constitución y que -como veremos- su Tribunal Constitucional declaró inicialmente la incompatibilidad constitucional de los derechos colectivos de estos pueblos ${ }^{34}$. Sin embargo, la jurisprudencia judicial, en general, ha avanzado evolutivamente reconociendo este derecho desde la aplicación del Convenio $\mathrm{N}^{\circ} 169$ de la OIT. ${ }^{35}$

Por otra parte, el reconocimiento del derecho fundamental a la identidad cultural nos sitúa en las cuestiones teóricas de lo que se ha denominado el "conflicto cultural", esto es, nos lleva al problema de la delimitación conceptual del principio de igualdad en las sociedades democráticas liberales y su capacidad de resolver la demanda por el reconocimiento de la diferencia cultural ${ }^{36}$, en nuestro caso de los pueblos indígenas ${ }^{37}$. Este debate se desplaza desde una negativa a que el pluralismo democrático y el principio de igualdad puedan alcanzar las reivindicaciones étnicas y culturales ${ }^{38}$, hasta una pretensión de valorización social y jurídica de la cultura, que, a su vez, exige la necesidad de fijar límites legales al reconocimiento y ejercicio de los derechos culturales ${ }^{39}$. Pero también encontramos nuevas concepciones que visualizan una construcción institucional posible y coherente con la realidad multicultural y democrática latinoamericana ${ }^{40}$. Desde nuestra mirada, se trata del desafío de resolver los problemas entre los valores de sistemas normativos, culturales y de creencias, distintos y no comparables,

\footnotetext{
32 Véase el concepto de "derechos emancipatorios" en: Ramírez, Silvina, Igualdad como Emancipación: Los Derechos Fundamentales de los Pueblos Indígenas”, Anuario Centro de Derechos Humanos, No 3 2007, Universidad de Chile, Santiago, 2007, 12, 18.

33 Vittor, Luis, "El ejercicio de la justicia indígena", en Aylwin, J. et al., Convenio No 169 de la OIT. Los desafíos de su implementación en América latina a 25 años de su aprobación, Copenhage, IWIGIA, 2014.

34 TC, Rol 309-2000.

35 Véase: Aylwin, José, et al, Los pueblos indígenas y el derecho, Santiago, LOM, O.C., 2013.

36 Honneth, Axel, "Redistribución como reconocimiento: Respuesta a Nancy Fraser", en N. Fraser, et al, ¿Redistribución o reconocimiento? Un debate político-filosófico, 89-148, Madrid, Morata, 127 - 133.

${ }^{37}$ Ramírez, op. cit., 35-37.

38 Mouffe, Chantal, El Retorno de lo Politico. Comunidad, Cuidadania, Pluralismo y Democracia Radical, B. Aires, Paidós, 1999; Honneth, Axel, La lucha por el reconocimiento. Por una gramática moral de los conflictos. Barcelona: Crítica, 1997.

${ }^{39}$ Kymlicka, Will, Multicultural Citizenship, Oxford, Oxford University Press, 1995; Cortina, Adela, Justicia cordial, Valencia, Trotta, 2010.

40 Ramírez, Silvina, Constitucionalismo y derechos de los pueblos indígenas, B. Aires, La Ley, 2013; Santos, Boaventura, Conocer desde el sur..., Lima, U. San Marcos, 2006; Yrigoyen, Raquel, "El horizonte del constitucionalismo pluralista: del multiculturalismo a la descolonización”, en C. Rodríguez (ed.), El derecho en América Latina..., 139159, B. Aires, S. XXI, 2011.
} 
considerando el contexto, la perspectiva histórica y la cosmovisión, entre otros" "41. Así, hablar del derecho a la identidad cultural, desde una perspectiva intercultural significa concebir la Justicia interculturalmente $\mathrm{o}$ en contexto ${ }^{42}$. En consecuencia, el ejercicio del derecho fundamental a la identidad cultural genera una tensión normativa, social y cultural, que nos plantea la necesidad concreta de estudiar los efectos de este derecho sobre los sistemas normativos que aún mantienen estructuras basadas en el monismo jurídico, como el de Chile.

\section{Derecho fundamental a la identidad cultural en Chile}

En primer término, en Chile, desde el punto de vista constitucional, el derecho fundamental a la identidad cultural se justifica en una visión amplia del principio de igualdad ${ }^{43} \mathrm{y}$ del respeto de la dignidad humana ${ }^{44}$ (arts. 1 inc. $1^{\circ}$ y $19 \mathrm{~N}^{\circ} 2$ ). De este modo, los pueblos indígenas, conforme el principio de igualdad constitucional referido -por sobre la prohibición de la discriminación, como diferenciación arbitraria, según se trata corrientemente-, gozan del derecho a ejercer y asumir la diferencia fundados en la dignidad de la persona humana, como manifestación del derecho fundamental y colectivo de los pueblos indígenas a su identidad cultural. Esta perspectiva justifica, en particular, la protección jurídica de las culturas indígenas y el derecho de sus respectivos integrantes a su identidad cultural. Al respecto, la igualdad no inhibe la existencia de estatutos o normativas especiales, frente a sectores o grupos vulnerados históricamente de la sociedad. Pero, la recomprensión del principio de igualdad que proponemos, en el sentido emancipatorio del derecho fundamental a la identidad cultural, implica que los pueblos indígenas tienen el derecho a interactuar normativamente conforme sus circunstancias propias y específicas, desde una perspectiva diversa culturalmente, lo que tensiona las concepciones e instituciones clásicas del ordenamiento jurídico constitucional, en especial respecto de la propiedad, la justicia y la toma de decisiones.

Entonces, siguiendo los estándares que exige el Convenio $\mathrm{N}^{\circ} 169$ de la OIT, se trata de un principio de igualdad que amplía la concepción de la ciudadanía a un conjunto de nuevas categorías de derechos establecidas en favor de los pueblos indígenas, incluso en su dimensión colectiva (aunque esto último ha sido objeto de debate en Chile ${ }^{45}$ ). Conforme con ello, la legislación chilena, también deben adecuarse a los estándares impuestos, a partir de la referida recomprensión de la igualdad y de los derechos de los pueblos indígenas internacionalmente reconocidos, bajo el respeto del derecho fundamental a la identidad cultural, como una nueva visión de la ciudadanía y la convivencia democrática en diversidad, con pleno respeto de los derechos de los pueblos indígenas.

\footnotetext{
${ }^{41}$ Ramírez, 2007, op. cit., 39-40.

42 Salas, Ricardo, Faundes, Juan Jorge, "Justicia e interculturalidad. Conflictos y desafíos jurídico-políticos en el Wallmapu (Chile)", en Marianella Ledesma (coord.), Justicia e Interculturalidad, análisis y pensamiento plural en América y Europa. Lima: Centro de Estudios Constitucionales - Tribunal Constitucional del Perú, 2018, 693-737.

${ }^{43}$ Solo desarrollamos aquí la fundamentación constitucional que se viene consensuando a partir de la ratificación del Convenio 169 de la OIT en 2008. En consecuencia, no abordamos, en profundidad, los cuestionamientos a la "capacidad" del principio de igualdad de dar cuenta de los requerimientos normativos del reconocimiento del derecho a la cultura, según recién enunciamos. Véase: Faundes, op cit, 2017a.

${ }^{44}$ CA Temuco, Rol 773-2008; CS, Rol 7287.

45 Donoso, Sebastián, "Chile y el convenio 169 de la OIT: reflexiones sobre un desencuentro", Temas de la agenda pública, Pontificia Universidad Católica de Chile, Año 3, N 16, abril, 2008.
} 
En particular, la jurisprudencia chilena ha reconocido en sus fallos el derecho a la cultura de estos pueblos, con diversos alcances, como parte del derecho esencial que la Constitución asegura "de intervenir con igualdad de condiciones en su mayor realización espiritual y material posible" (art. 1 inc. $5^{\circ}$ ), invocando al efecto el Convenio 169 de la OIT como tratado internacional de derechos humanos vigente. Al efecto, la tesis mayoritaria considera que a partir de la reforma al artículo 5 de la Constitución de 1989, las normas de derechos humanos contenidas en los tratados de derechos humanos ratificados por Chile tienen aplicación preferente, porque los derechos humanos pasan a ser un auténtico límite para el ejercicio de la soberanía por parte de los organismos del Estado. Sin embargo, aún resulta difícil plantear que se haya asegurado con claridad el derecho fundamental a la identidad cultural por esta vía ${ }^{46}$. Más bien, la emergencia del derecho fundamental a la identidad cultural de los pueblos indígenas en Chile se ha ido dando bajo una tensión entre negación y reconocimiento, generando un grado importante de indeterminación de este derecho ${ }^{47}$, lo que nos exige un esfuerzo interpretativo -aún en desarrollo- para la conceptualización del derecho, como marco base de delimitación del mismo. Con todo, la jurisprudencia indicada sí ha incluido en diversas sentencias consideraciones que refieren al derecho a la identidad cultural o, a lo menos, a derechos culturales de los pueblos indígenas en virtud del Convenio 169 de la OIT $^{48}$. Solo a modo ejemplar, ha dicho la Corte Suprema que:

... recepcionando así el derecho consuetudinario y hábitos del pueblo pehuenche como fuente de derecho, de modo de hacer compatible la sanción penal prevista en nuestra legislación general con las características económicas, sociales y culturales de esa etnia [y que] atendido el contexto social cultural en que se encontraban inmersos al momento de la comisión de los ilícitos sancionados en este procedimiento ${ }^{49}$.

Asimismo, ha planteado la Corte de Apelaciones de Temuco que:

... especial atención deben tener los Estados en la protección y preservación de las tierras y culturas indígenas en todas sus manifestaciones... se vulnera la integridad física y psíquica de esa etnia, se agravia en su naturaleza humana y la calidad de vida y en la protección de sus sistemas de salud, puesto que el Menoko es un lugar, espacio cultural, que no debe ser molestado, sino que siempre protegido" 50 .

La Corte Suprema también señaló que:

... en el sector materia de autos, existen comunidades indígenas y lugares de significación cultural, susceptibles de ser afectados [y] en dicho entendido, y considerando que la servidumbre solicitada es susceptible de afectar pueblos y personas indígenas... previo a un pronunciamiento... debió

${ }^{46}$ CS, Rol 7287-2009; CS, Rol 2840-2008; CS, Rol 10.090-2011; TC, Rol 2387-2012; TC, Rol 2552-2013.

47 Carmona, Cristobal, "Hacia una comprensión "trágica" de los conflictos multiculturales: acuerdos reparatorios, VIF y derecho propio indígena”, Revista Chilena de Derecho, V. 42, N 3, 975-1001, 2015, 984.

48 Porma, 2017, op cit.

${ }^{49}$ CS, Rol 2683-2010.

${ }^{50}$ CA Temuco, Rol 1773-2008; CS, Rol 7287- 2009. 
tramitarse conforme a la institucionalidad vigente, la consulta indígena previa que se viene refiriendo" 51 .

Más recientemente y ampliando sus prevenciones iniciales, el Tribunal Constitucional chileno planteó que el Convenio $\mathrm{N}^{\circ} 169$ de la OIT establece que el Estado deberá "respetar la importancia especial que para las culturas y valores espirituales de los pueblos interesados reviste su relación con las tierras y territorios" (art. 13) ${ }^{52}$.

Entonces, como vemos, incluso bajo la visión más conservadora del Tribunal Constitucional chileno, el principio de igualdad constitucional comprende, en un sentido amplio y evolutivo, el derecho fundamental radicado en la dignidad intrínseca de toda persona a desenvolverse y desarrollar su vida conforme todos los aspectos de su identidad personal, como miembro de un grupo específico que comparte valores culturales, espirituales, religiosos y normas sociales, entre otros (una cosmovisión y una cultura de origen ancestral en el caso de los pueblos indígenas).

Conjuntamente, el derecho a la identidad cultural en Chile se ve reforzado por un conjunto de otras garantías constitucionales relacionadas, tales como: el "respeto y protección a la vida privada y a la honra de la persona y su familia" (art. $19 \mathrm{~N}^{\circ}$ 4) que se ha entendido inclusiva del derecho fundamental a la identidad personal ${ }^{53}$; y la libertad de conciencia y de culto $\left(19 \mathrm{~N}^{\circ} 6\right)^{54}$. Al mismo tiempo, el principio de igualdad considera el derecho a la igual protección de la ley, a las garantías del debido proceso, bajo una justa y racional investigación, lo que comprende la defensa de base argumental cultural en el proceso penal (19 $\mathrm{N}^{\circ}$ 3). Conjuntamente, la Convención Americana de Derechos Humanos asegura el derecho a un debido proceso en materia penal y a un "procedimiento sencillo, rápido y eficaz", para el reclamo y el ejercicio de los derechos (arts. 8 y 25), lo que incluye el derecho del imputado a presentar peritajes (antropológicos en nuestro caso).

Por último, el derecho fundamental a la identidad cultural de los pueblos indígenas, bajo la fundamentación antes explicada, se concretiza en dos garantías constitucionales conexas: el derecho a vivir en un medio ambiente libre de contaminación y la protección del dominio (amparando la propiedad indígena). Ambas confluyen en la protección de los derechos territoriales indígenas, en tanto bábitat y territorios indígenas (art. 13 a 16 Cv. 169) ${ }^{55}$. A modo de ejemplo, una sentencia emblemática fijó el alcance constitucional del concepto de "territorio" y su directa relación con el de "bábitat", integrando "los derechos culturales y la protección del medio ambiente", en relación a los derechos de los pueblos indígenas, amparados en Chile a partir de la ratificación del Convenio $\mathrm{N}^{0} 169$ de la OIT ${ }^{56}$. Señaló este fallo que se había vulnerado la garantía constitucional "del derecho a vivir en un medio ambiente libre de contaminación” (19 No 8), adscribiendo expresamente a una interpretación amplia del concepto de "medio ambiente" que incluye la protección de los elementos culturales

\footnotetext{
51 CS, Rol 6.628-2015.

52 TC, Rol 2552-214.

53 TC, Rol 1340-2009. Jurisprudencia reiterada en fallos Roles Nºs 1537, 1563, 1656.

54 En este sentido se acogió en la sentencia de la CA de Valdivia, Rol 501-2011. Sin embargo, la CS, Rol 3.863-

2012, rechazó el recurso, basada en la falta de titularidad sobre tierra indígena.

${ }^{55}$ CS, Rol 2840-2008; CS, Rol 14.003-13; CS, Rol 3.010-2013; CS, Rol 6.628-2015; TC, Rol 2552-2014.

${ }^{56}$ CA de Temuco, Rol 1773-2008, CS, Rol 7287- 2009.
} 
propios de la cosmovisión indígena mapuche ${ }^{57}$.

\section{El peritaje antropológico, "ariete emancipatorio" en la defensa penal cultural en Chile}

Ya planteada una conceptualización preliminar y una justificación normativa del derecho fundamental a la identidad cultural, nos interesa revisar cómo y en qué medida este derecho puede tener concreción efectiva mediante el peritaje antropológico.

La entrada en vigencia en Chile del Convenio 169 de la OIT en 2009, como tratado de derechos humanos, exige al Estado adecuar su sistema de justicia para dar efectividad al derecho fundamental a la identidad cultural trastocando sus bases liberales cerradas a la inclusión de las diferencias culturales. Y, como dijimos, a falta de reformas legales suficientes, el giro se centra en la jurisprudencia judicial y su capacidad de expandir una hermenéutica evolutiva de los derechos humanos. Mientras, el derecho fundamental a la identidad cultural se concretiza en el derecho del imputado/a indígena a reclamar la relevancia penal del contexto cultural en que se circunscribe el hecho o hechos por los que se le persigue penalmente, desarrollando lo que se conoce como una "defensa cultural"58. Así, un punto de vista interdisciplinario, el derecho fundamental a la identidad cultural, expresado concretamente en la defensa cultural, arroja el importante desafío para las Ciencias Jurídicas y Sociales de buscar las soluciones frente a las cuestiones trascendentes de la realidad social. Este desafío es especialmente necesario en contextos de violencia interétnica, como la que se vive en el $W$ all Мари. Se trata de un esfuerzo epistemológico, metodológico que articule identidad cultural y derecho, usando el peritaje antropológico como un medio de prueba en lo judicial y un mecanismo que comunica referentes cognitivo-normativos distintos en lo cultural. En este sentido, el peritaje antropológico es, precisamente, un campo para el desarrollo de una epistemología emancipatoria, fronteriza e interdisciplinaria, situada en un contexto social conflictuado, cuya operación presenta un alto impacto normativo ${ }^{59}$. Como señala FornetBetancourt, a partir de la constatación de una sociedad tecnológica moderna como un contexto violento para el diálogo intercultural, emerge la necesidad de encontrar un equilibrio epistemológico que sea "reflejo teórico de la pluralidad de conocimientos" y, al mismo tiempo, presupuesto de "una reconfiguración pluralista de la vida y su conservación en la tierra" "60.

En relación con los sistemas de justicia latinoamericanos, en particular, se ha constatado en los estados un uso progresivo del peritaje antropológico como una herramienta dentro de la defensa penal especializada enfocada en comprender y valorar las diferencias socioculturales de los imputados indígenas, como garantía jurídica de las sociedades pluriétnicas y

\footnotetext{
${ }^{57}$ Aylwin, op. cit., 275-276.

${ }^{58}$ La literatura refiere a cultural defences, como una causa de exclusión o de atenuación de la responsabilidad penal de un sujeto perteneciente a una minoría étnica con cultura, usos y costumbres distintos o incluso en conflicto con los de la cultura del sistema anfitrión. De Maglie, Cristina. Los delitos culturalmente motivados ideologías y modelos penales, Madrid, Marcial Pons, 2012, 136.

59 Véase un esfuerzo bajo es enfoque en: Lombraña, Andrea, Carrasco, Morita (Edts.), Experiencias de lectura insolente: abordajes empíricos en el campo jurídico, B. Aires, Antropofagia Ed., 2018.

${ }^{60}$ Fornet-Betancourt, Raúl, "La pluralidad de conocimientos en el diálogo intercultural”, en David Mora (ed.), La pluralidad de conocimientos en el diálogo intercultural, La Paz, Convenio Andrés Bello, 9-20, 2009b, 10.
} 
multiculturales $^{61}$. En este aspecto, se ha llegado a considerar, en sí, el derecho a la pericia cultural o antropológica como un derecho fundamental (procesal) emergente e innominado que facilitaría el acceso y la realización de justicia hacia personas grupos, comunidades y pueblos vulnerables social, económica y políticamente",62

Sin embargo, esta perspectiva también es objeto de críticas que ubican al peritaje antropológico como instrumento de subordinación jurídico procesal. En concreto, el uso del peritaje antropológico ha "vacilado" entre un uso "funcional" a los sistemas de justicia estatal y una jurisprudencia de mayor despliegue "emancipatorio". Pero, incluso en los casos inicialmente más avanzados se han visto procesos de contracción posterior, como con la paradigmática Corte Constitucional de Colombia a partir de $1991^{63}$. Con todo, por sobre las limitaciones o involuciones indicadas, podemos sostener -a lo menos como hipótesis de trabajo-, que con la emergencia del derecho fundamental a la identidad cultural se presentan perspectivas potencialmente emancipatorias -aún no consolidadas- en que la pericia antropológica es central. Entonces, debe aclararse que el peritaje antropológico, conforme la epistemología en que se base, puede considerarse desde dos puntos de vista diversos. Uno, funcional al Estado de Derecho imperante. $Y$ un segundo enfoque emancipatorio que defendemos en este trabajo. Luego, estamos de acuerdo con Sánchez y Gómez cuando sostienen que el objeto del peritaje antropológico es "ubicar las características y estructuras propias del sistema particular de cada pueblo y no extender nuestro propio mundo para encontrarlo allá" definición de los comportamientos y la aplicación de penas y procedimientos, dentro de formulaciones preestablecidas por el Derecho Positivo", basado en un imperativo, en la transgresión y respectiva sanción, bajo un procedimiento formal dado. Por el contrario, la visión antropológica que sustenta nuestro enfoque del peritaje antropológico, contiene una metodología donde el interés principal de la relación Derecho positivo y sistema normativo indígena se centra en una solución de conflictos cuyos medios se articulan con la cosmovisión que comprende la totalidad de la vida de un pueblo, su relación con la forma de organización social, de producción y el sistema de creencias. Y no la búsqueda de un "derecho interno" del pueblo indígena estudiado, para encontrar y distinguir normas, civiles, administrativas y penales, respectivos procedimientos y respectivas autoridades competentes. Seguir este razonamiento implicaría suponer inferiores a aquellos grupos a quienes se aplica, al extender (imponer) el derecho positivo occidental a otros pueblos ${ }^{65}$. En este sentido, recogemos la

${ }^{61}$ U.C. Temuco, Defensoría Penal Pública, "Modelo de gestión de peritaje antropológico MoGPA", Proyecto Fondef-Idea "Peritaje antropológico para la Defensa Penal en contextos de diversidad cultural", N ID14I 10379 (2014-2017), 2016, 16-18.

62 Ruiz, Juan Carlos, “Aproximación a los fundamentos constitucionales del peritaje antropológico", en A. Guevara Gil, A. Verona y R. Vergara (eds.), El peritaje antropológico. Entre la reflexión y la práctica, Lima, Centro de Investigación, Capacitación y Asesoría Jurídica del Departamento Académico de Derecho (CICAJ), $2015,132$.

${ }^{63}$ Sánchez Botero, Ester, El peritaje antropológico Justicia en clave intercultural, Bogotá, GTZ, 2010; Entre el juez Salomóm y el Dios Sira. Decisiones interculturales e interés superior del niño, Bogotá, Iniversiteit van Amsterdam, Faculteit del Reechtsgeleerdheid -UNICEF, 2006; Sánchez Botero, Ester, Gómez, Herinaldy, El Peritaje Antropológico, Como Prueba Judicial, Bogotá, RELAJU - ICAH, 2008.

${ }^{64}$ Sánchez Botero, Gómez, 2008, op. cit., 17.

${ }^{6}$ Idem. También, Carmona, Cristobal, "Entrando al círculo: la antropología jurídica y la posibilidad de justicia intercultural”, en, M. Castro (Ed.), Los Puentes entre la Antropología y el Derecho. Orientaciones desde la Antropología 
propuesta de Carmona de buscar "posibilidad de justicia", para superar el rigor dogmáticoepistemológico y avanzar con la suficiente imaginación para "des-armar y armar al derecho, acomodando sus prácticas y narraciones en torno a una inclusión ética de la diversidad"

Conforme lo expuesto, consideramos que para superar las críticas al peritaje antropológico (por sus efectos funcionalistas) es necesario, previamente, un cambio de paradigma éticoepistemológico, dado por la referida "ética de la diversidad" como base del derecho fundamental a la identidad cultural. Así, la pericia antropológica solo podrá facilitar una efectiva transformación intercultural, primero, si se invoca desde el derecho fundamental a la propia cultura, entendida como elemento constitutivo del ser, en lo personal y en relación con otros, particularmente, como presupuesto de la sobrevivencia misma de los pueblos indígenas. Segundo, en especial para enfrentar el sistema penal, solo será posible hablar de un paradigma emergente que tiene la potencialidad de "fisurar" el sistema jurídico, si se proponen categorías nuevas, flexibles, pertinentes y si se realizan acciones efectivas para ejercer el derecho a la identidad cultural como derecho fundamental que enfrenta y cuestiona en concreto los paradigmas previamente imperantes en el Derecho.

De esta manera, el peritaje antropológico se presenta como un instrumento capaz de articular los referentes culturales indígenas y el Derecho del Estado, porque operativiza en la práctica forense el derecho fundamental a la identidad cultural, permitiendo comprender y valorar, antropológica y jurídicamente, las diferencias históricas, sociales y culturales en las que se desenvuelven los indígenas imputados de determinados delitos. Trasciende su naturaleza meramente formal (medio de prueba), para introducir en el proceso penal la dimensión cultural de las conductas sometidas a escrutinio judicial, con efectos jurídicos relevantes y emancipatorios. Sin embargo, la utilización de la pericia antropológica, aunque con impacto importante en los últimos años, aún adolece de una regulación difusa y con frecuencia es infravalorada. Ello, exige, desde ya, el desarrollo de un de peritaje antropológico culturalmente pertinente a la identidad cultural de los imputados indígenas y, al mismo tiempo, eficiente en la incorporación "experta" (antropológicamente hablando) del marco cultural indígena al proceso penal $^{67}$. Por ejemplo, en Chile, a la fecha solo el Modelo de Defensa Penal Indígena de la Defensoría Penal Pública fija estándares para el peritaje antropológico, pero aún de forma insuficiente $e^{68}$.

No obstante estos problemas, en los casos que revisaremos a continuación, han sido los peritajes antropológicos los medios que principalmente han permitido articular el derecho positivo del Estado con la realidad sociocultural indígena, sobre la base de una Antropología aplicada al contexto cultural y normativo ${ }^{69}$. Dicha Antropología potencia el peritaje

Juridica, Santiago, PRANJU Universidad de Chile, 379-404, 2014, 388-393.

${ }^{66}$ Ibid, 396.

67 Véase: U.C. Temuco, Defensoría Penal Pública (DPP), "Modelo de Gestión del Peritaje Antropológico" (MoGPA), Proyecto Fondef-Idea Peritaje antropológico para la Defensa Penal en contextos de diversidad cultural, N ID14I 10379, 2017, 16-18

${ }^{68}$ DPP, Modelo de Defensa Penal Indigena, 2012.

${ }^{69}$ La Dra. Teresa Durán, de la Universidad Católica de Temuco por décadas desarrolló la que denominó una

"Antropología activa" que encarna una epistemología comprometida y emancipadora en contexto Mapuche.

Véase: Durán, Teresa, Berho, Marcelo, Carrasco, Noelia, Mora, Héctor, Antropología desde el sur. Obras escogidas de Teresa Durán, Temuco, Ed. U.C. Temuco. 
antropológico, viabilizando y facilitando el ejercicio del derecho fundamental a la identidad cultural de los pueblos indígenas.

\section{Experiencias y problemas dogmáticos de la defensa penal cultural}

Situándonos en el Sistema Penal, donde el Estado despliega su mayor nivel de control y con las consecuencias de legitimación del uso de la fuerza y la potencial privación de libertad, será en este ámbito dónde el reconocimiento del derecho fundamental a la identidad cultural cobre amplia relevancia, abriendo espacios al reconocimiento del "derecho propio" indígena, enunciado como "costumbre indígena", "derecho consuetudinario", "instituciones propias" u otras categorizaciones. Entonces, el desafío es facilitar el desarrollo de los mecanismos institucionales que permitan articular y resolver los conflictos que puedan generarse ante el reconocimiento de la identidad cultural, sin dejar de consolidar los estándares internacionales de derechos humanos. Se trata de procurar mecanismos y procedimientos que, por una parte, permitan la resolución autónoma de los conflictos de orden normativo; y, por otra, frente a potenciales conflictos de orden cultural, procuren asegurar los mínimos concernientes a la dignidad humana, sin dejar de recomprender los derechos humanos en contexto ${ }^{70}$. En este marco, aunque la jurisprudencia chilena no ha sido uniforme, muestra una tendencia al reconocimiento de este derecho en el ámbito penal que nos permite identificar, a lo menos, tres materias en la defensa de personas indígenas centradas en el derecho a la identidad cultural $^{71}$.

Una primera materia que encontramos está asociada a la validación de las formas en que los miembros de los pueblos indígenas resuelven sus conflictos y o sancionan los delitos cometidos por sus miembros. La segunda, refiere al tratamiento diferenciado en las formas de cumplimiento de las penas. Y, la tercera, corresponde a cómo desde la perspectiva de las categorías dogmático penales de la teoría del delito (Derecho Penal estatal) se aborda la "defensa cultural" o el llamado "delito culturalmente motivado" (como categorización genérica que requiere desarrollar un conjunto de precisiones) ${ }^{72}$.

En el marco del primer tópico, se suscitó en los tribunales chilenos una discusión en torno a los derechos culturales de los pueblos indígenas a la luz de acuerdos reparatorios en causas de violencia intrafamiliar suscitadas entre indígenas, conforme la aplicación de los artículos 9 y 10 del Convenio 169, para obtener salidas alternativas a las sanciones penales privativas de libertad. Estos acuerdos se encuentran expresamente prohibidos por la legislación chilena en materia de violencia doméstica, en razón de la protección de los derechos fundamentales de la mujer ${ }^{73}$. Sin embargo, dichos acuerdos fueron aprobados judicialmente invocando el Convenio 169 que da preferencia a las formas en que los pueblos indígenas han definido para la represión

\footnotetext{
${ }^{70}$ Con este fin asumimos "un enfoque intercultural de los derechos humanos" que puede revisarse en Faundes, Juan Jorge, 2015b, op. cit.. También, entre otros, en: Villegas, Myrna, Mella, Eduardo, Cuando la costumbre se convierte en ley. La cuestión penal y la pervivencia de los sistemas sancionatorios indígenas en Chile, Santiago, Lom, 2017, 140-150.

71 Entre otros: TOP Temuco, RIT 49-2006; CS, Rol No 2683-10; CA Temuco, Rol No RPP-388-2012; CA Temuco, Rol No 635-2012; CA Temuco, Rol 499-2012; CS, Rol 10.635-2011; TOP Arica, RUC 1410018700-1, RIT 27-2015.

${ }^{72}$ De Maglie, 2012, op. cit.

73 Artículo 19 de la Ley 20.066, en relación con el artículo 241 del Código Procesal Penal.
} 
de los delitos cometidos por sus miembros (art. 9). En consecuencia, en base a estas normas se permitió incluir el principio del "restablecimiento del equilibrio" propio del derecho indígena mapuche, como forma tradicional de resolución de conflictos de este Pueblo ${ }^{74}$. $^{75}$

En estos casos, en relación a la noción de "conflicto cultural" y su recepción normativa, se ha sostenido que se trata de un conflicto entre el sentido retributivo de la resolución del conflicto penal, conforme el derecho del Estado, y la lógica restaurativa, propia de las formas tradicionales indígenas ${ }^{76}$. Es decir, una conducta considerada delito para la cultura dominante, también resulta una acción desvalorada en la cultura indígena, aunque en esta cultura puede recibir un tratamiento social y normativo distinto al reproche o "sanción". Por ejemplo, el Pueblo Mapuche históricamente tuvo $-\mathrm{y}$ en diversa medida contextual sigue teniendo- una organización política, social y cultural propia, vinculada a los principios de igualdad, reciprocidad, redistribución y horizontalidad. Esa forma de organización se articula mediante un sistema normativo conocido como $A$ z Maрu que considera métodos de resolución de los conflictos asociados a los respectivos miembros de cada $\operatorname{lof}^{77}$. El $A z$ Mapu está conformado por las "pautas de conducta que se transmiten de generación en generación por la vía oral y que regulan las relaciones sociales y su vinculación con el entorno natural" ${ }^{78}$, de tal forma que dicho sistema de justicia constituye una institucionalidad propia con sus agentes, procesos y espacios de acción ${ }^{79}$. En relación con la sociedad chilena mayoritaria, estas pautas de regulación son diversas, aunque no necesariamente opuestas. Y, en el caso de que sean transgredidas, las respuestas dadas por el sistema de regulación mapuche frente a actos transgresores no son de naturaleza punitiva, sino que corresponden más bien a mecanismos de autocomposición, en los cuales el centro de protección es la comunidad ${ }^{80}$. Como explican Villegas y Mella, los fines de la pena en los sistemas sancionatorios indígenas deben examinarse "a la luz del principio rector de reciprocidad" y de lo que denominan como el "bien jurídico colectivo" del "equilibrio de las fuerzas comunitarias y del cosmos". Conforme ello -dicen- los sistemas de justicia indígena "tienden a identificarse con la justicia restaurativa" porque la sanción no busca castigar sino, en general, "acoger nuevamente al individuo que se ha desviado de las reglas de la comunidad". En este contexto, reconocen varios posibles fines positivos específicos, tales como el preventivo para la reinserción del sujeto a la comunidad y en ciertos casos para el establecimiento de la responsabilidad familiar por su obligación de mantener la conducta correcta del infractor. ${ }^{81}$

\footnotetext{
${ }^{74}$ CA Temuco, Rol 388-2012.

${ }^{75}$ Este tema ha tenido amplia cobertura bibliográfica, entre otros: Carmona, 2015, op. cit; Villegas Mella, 2017, op. cit., 151-163; Nash, Claudio, et al, Erradicación de la Violencia Contra las Mujeres en las Américas..., Santiago, Centro de Derechos Humanos, Universidad de Chile, 2013.

${ }^{76}$ Carmona, op. cit., 996.

77 Espacio territorial limitado por espacios naturales como ríos, montes, bosques, conformado por familias emparentadas, patrilinealmente, que poseen un origen y ascendencia común. Mariman, 2006, op. cit., 275.

${ }_{78}$ Melin, Miguel, Coliqueo, Patricio., Curihuinca, Elsy., Royo, Manuela, AZMAPU: Una aproximación al sistema normativo Mapuche desde el Rakizuam y el Derecho Propio, 2016, 34.

${ }^{79}$ Mariman, 2006, op. cit., 65.

80 Villegas, Myrna, "Sistemas Sancionatorios indígenas y Derecho Penal ¿Subsiste el Az Mapu?”, Política Criminal, Vol. 9, N 17, 213-247, 2014, 217.

81 Villegas, Mella, op. cit., 74-75.
} 
Una segunda materia dice relación al tratamiento diferenciado en el cumplimiento de las penas (art. 10 del Conv.169), tanto en la decisión jurisdiccional de establecer formas no privativas de libertad para el cumplimiento de ellas, como en el tratamiento culturalmente pertinente en el ámbito intrapenitenciario (al momento de cumplir la condena) ${ }^{82}$.

El tercer ámbito normativo, corresponde a la "defensa penal cultural", en que la dogmática penal ha usado categorías como el "error de prohibición", el "error de comprensión" y la "inimputabilidad", que se contraponen con las del "ejercicio legítimo de un derecho" y la "atipicidad" 83 , planteadas desde el derecho fundamental a la identidad cultural. Al efecto, un avance lo plantea Beatriz Kalinsky quien propone críticamente una renovación en la dogmática penal aplicada a la persecución penal de personas indígenas que llama "un concepto renovado de inimputabilidad" -aunque consideramos que dada su propia explicación debiera derechamente prescindir del concepto de "inimputabilidad"-. Conforme esta proposición, la prueba antropológica confronta a los jueces con una "epistemología nativa" (la cosmovisión indígena), de tal forma que esta pericia no deja "resquicio para evitar la mirada de quien está siendo juzgado y de su contexto de referencia". Luego, cuando se asume la pluralidad de culturas en el proceso penal se abren las posibilidades de introducir las creencias para explicar y actuar sobre la realidad. Por ejemplo, señala Kalinsky que en el caso de los homicidios rituales: "... hay un componente de intención (dolo) pero que debe ser evaluado dentro del contexto donde se produce la ofensa [por lo tanto] no hay error, no hay inimputabilidad en los términos vigentes del Código Penal..." ${ }^{\Perp 4}$.

Al respecto, aunque no es nuestro objetivo desarrollar aquí un análisis dogmático penal exhaustivo, solo con la finalidad de informar el alcance de este tercer problema general asociado al derecho a la identidad cultural en materia penal, reseñaremos algunos casos ejemplificadores. En todos ellos, un factor central que ha permitido la revisión de las conductas en el contexto o marco de referencia en que ellas ocurrieron, han sido los peritajes antropológicos. ${ }^{85}$

En Chile, podemos destacar el denominado "Malón de Caiñicu" (2012), caso correspondiente a un delito de homicidio en que se aplicó una eximente de responsabilidad penal basada en razones socioculturales, como el haber actuado en "lealtad" a su Lonko como autoridad tradicional, conforme las prácticas ancestrales ${ }^{86}$. Encontramos también varios casos referidos al porte, comercialización y uso de hoja de coca, como actividad tradicional indígena

\footnotetext{
82 Por extensión no la abordamos aquí. Puede revisarse UC Temuco, DPP, 2017, op. cit.

83 Beatriz Kalinsky propone una breve tipología que problematiza el abordaje dogmático penal frente a la pluralidad cultural con la que podemos coincidir en varios puntos. Pero en este trabajo avanzamos en la cuestión de la atipicidad (que la autora no incluye) y del ejercicio legítimo de un derecho, al que solo refiere indirectamente para preferir "el error de comprensión culturalmente condicionado" como solución dogmático penal "acertada... por el momento”. Kalinsky, Beatriz, Justicia, Cultura y Derecho Penal, B. Aires, Ad-Hoc S.R.L., 2000, 156-161. Por su parte, Cristina de Maglie hace un interesante desarrollo usando las categorías "soluciones de la tipicidad", "Hechos culturalmente motivados y Antijuridicidad" y "Hechos culturalmente motivados y ejercicio del Derecho”. De Maglie, 2012, op. cit., 193-237.

${ }^{84}$ Kalinsky, 2000, op. cit., 245-247.

${ }^{85}$ También se pueden pesquisar algunos casos muy interesantes en que se ha aceptado el testimonio de machi, como autoridad tradicional para explicar asuntos de la cosmovisión mapuche (enfermedad mapuche o mapu kutran), bajo la forma de testigo experto. TOP Temuco, RIT 107-2013, 2013.

${ }^{86}$ JL Santa Bárbara Rol No 2.683-10; Corte Suprema, Rol 2683-2010.
} 
basada en la identidad cultural de los pueblos indígenas andinos ${ }^{87}$. En esta materia en particular, luego de sucesivos fallos condenatorios, la jurisprudencia giró absolviendo a los imputados indígenas del delito de tráfico de estupefacientes. Pero las absoluciones se fundaron en distintas categorías dogmáticas, bajo soluciones penales muy dispares. Desde la perspectiva descrita, los alcances de conceptos como el de "error de prohibición", "error de comprensión" y el de "inimputabilidad", se distancian sustantivamente de la argumentación asociada a prácticas indígenas legítimas, que la defensa cultural puede tratar como "ejercicio legítimo de un derecho", argumentando falta de "antijuricidad", o derechamente "atipicidad".

El debate indicado lo podemos explicar a la luz de un caso de 2015 asociado a la hoja de coca que absolvió a un acusado de origen Aymara argumentando que "no actuó con un 'dolo' de traficar, pues se encuentra amparado en un error de prohibición". En resumen, si bien la conducta de comerciar hoja de coca fue considerada "típica" (que se corresponde con la descripción del delito contemplado en la ley) y "antijurídica" (que la misma ley no excluye la responsabilidad penal por alguna causal específica), los jueces estimaron que al acusado "lo gobierna la ignorancia de la antijuridicidad de la norma" ("error de prohibición"). En una primera lectura, estos argumentos parecen distanciarse de una perspectiva de reconocimiento del derecho a la identidad cultural porque invocan la "ignorancia" o el "error" de parte del imputado indígena, en lo que subyace un estereotipo que podría considerarse racista, más allá de que los jueces, quizás, solo buscaban evidenciar la existencia de un factor cultural significativo (y ello pudo ocurrir, eventualmente, por un déficit en la argumentación dogmática penal, más que en una voluntad discriminadora). En este sentido, ya en una segunda lectura de otros acápites del mismo fallo, conciliable con el mismo derecho a la identidad cultural, los sentenciadores también fundamentaron su veredicto en la importancia espiritual, religiosa, cultural y medicinal que tiene la hoja de coca para el Pueblo Aymara. En consonancia con ello, invocaron el Convenio 169 de la OIT (art. 9), como instrumento vinculante para el Estado de Chile que los obligaba a garantizar el respeto a la identidad de los pueblos indígenas, lo que requiere en materia de responsabilidad penal ponderar las particularidades sociales y culturales de los integrantes de estos pueblos ${ }^{88}$, con lo que dejaron asentado en esta decisión judicial -lo que podemos denominar- un "germen" emancipatorio.

Con mayor claridad, un supuesto dogmático penal absolutorio, armónico con el derecho fundamental a la identidad cultural de los pueblos indígenas, es el del "ejercicio legítimo de un derecho, autoridad, oficio o cargo ${ }^{89}$. Así, esta categoría nos parece procedente en casos de imputaciones por el delito de usurpación, respecto de acciones enmarcadas en reivindicaciones territoriales indígenas de tierras de uso ancestral demandadas por comunidades mapuche o conexas a ellas, como el hurto de madera o la usurpación de aguas respecto de dichos predios. Este argumento de legitimidad es posible de fundar en el derecho de que gozan los pueblos indígenas a las tierras que ocupan o poseen "de una u otra manera", así como a los recursos

\footnotetext{
${ }^{87}$ Barrientos Pardo, Ignacio, “Licitud del porte y uso de la hoja de coca”, Política Criminal, N 5, 2008, A 4-5, 1-30, 2008. DPP, $2^{\circ}$ Informe de jurisprudencia sobre defensa penal de imputados indígenas, 2013.

${ }^{88}$ JG Arica, RIT, 648-2013.

${ }^{89}$ Actúa justificado quien ejercita un derecho que le ha sido conferido por el ordenamiento jurídico. Puede tratarse de una facultad expresamente contemplada en la ley o en normas consuetudinarias. Cury, Enrique, Derecho Penal. Parte General. Santiago: Ediciones Universidad Católica de Chile, 2005, 381-382.
} 
naturales existentes en estas tierras y territorios ${ }^{90}$. Aunque la práctica judicial ha sido renuente a su aceptación dos casos son útiles ejemplarmente, más allá de sus resultados finales.

En el primero, de 2001, un grupo de aproximadamente 50 personas, pertenecientes a la Comunidad Indígena Domingo Trangol, comuna de Victoria, Chile, entre los que se encontraban hombres, mujeres y niños, ocuparon pacífica y simbólicamente por algunas horas el acceso a un predio forestal. La manifestación se acompañó de una declaración pública de la Comunidad Indígena. Paralelamente, a la misma hora el Lonko de dicha comunidad y otros dos integrantes de la comunidad, entregaron en la ciudad de Temuco, públicamente, una carta petitoria dirigida a la Intendente Regional. Demandaban al Gobierno de Chile, principalmente, la restitución de sus tierras ancestrales usurpadas. Asimismo, solicitaron que la autoridad regional contribuya en el acercamiento de las partes para entablar un proceso de diálogo con el fin de solucionar el conflicto territorial a través de los mecanismos legales existentes. Pero, estas acciones dieron lugar a una instrucción penal por cinco delitos agravados ${ }^{91}$. Para nuestros efectos, llama la atención cómo la demanda legítima ante el Estado de los derechos territoriales históricos usurpados "mutó" en el tipo penal de extorsión, sumado al delito de usurpación".

En el segundo, de 2013, se presentó una querella por usurpación contra una mujer mapuche que vía en un campo por más de 30 años sin títulos formales. Su defensa sostuvo que el predio "nunca ha dejado de ser poseído por personas mapuches", conforme la evidencia que proviene del "Título de Merced No 2.387 de 30 de Diciembre de 1912". Agregó que en 1993 se adjudicó la hijuela en cuestión a su tía (también mapuche de la comunidad), de quien ella heredó la tierra, "mientras que la querellante nunca ha estado en posesión material del inmueble" 93 . La querellante era una persona no indígena que adquirió el dominio como consecuencia de una compra inscrita, amparada en un resquicio legal. Asimismo, la defensa sostuvo que no era un asunto penal ("atipicidad") porque la querellada era titular de la propiedad conforme la costumbre mapuche y el reconocimiento que el Convenio 169 de la OIT (arts. 13 y 14) hace de su uso tradicional de la tierra. Los jueces desestimaron la defensa aceptando la tesis (muy dudosa conforme otra jurisprudencia civil") de que no se trataba de "tierra indígena" podemos observar, la misma conducta considerada ilícita penalmente -“usurpación”-, debió estimarse una forma de posesión indígena legítima de las tierras si se hubiese acogido el argumento histórico cultural de la defensa, considerando el derecho a la tierra en la base de la identidad cultural mapuche como Pueblo (en el caso no hubo peritaje antropológico) ${ }^{96}$.

\footnotetext{
${ }^{90}$ Conforme los artículos 13, 14 y 15 del Convenio $\mathrm{N}^{\circ} 169$ de la OIT.

91 Entre otros, los delitos de usurpación y el delito de "exacción ilegal” (tipo especial de extorsión a la autoridad, fundado en las reivindicaciones que contiene la carta que los imputados entregaron a la Intendente Regional. JG Victoria, RUC 231-7, 2001.

92 Si bien el caso significó una prolongada prisión preventiva para los tres indígenas imputados, finalmente la Fiscalía no perseveró en la acción penal y esta comunidad mapuche aún reivindica sus derechos territoriales.

93 CA Temuco, Rol 130-2013.

94 JL Loncoche, Rol C-374-2014; CS, Rol 45763-2017; CA Temuco, Rol 1.865-2008; CS, Rol 7.655-2008.

${ }^{95}$ La Corte Suprema finalmente desechó el caso, en voto dividido (tres a dos). JG Villarrica, RUC 1010033388-6, RIT 1494-2010; CA Temuco, Rol 130-2013; CS Rol 2145-1316.

${ }^{96}$ Nicolás Becerra, en el marco de la legislación argentina, coincide con esta tesis, aunque es escueto en la cuestión dogmática penal y argumenta en razón del principio de especialidad y de la jerarquía constitucional del reconocimiento de los pueblos indígenas de ese país. Becerra, Nicolás, Derecho penal y diversidad cultural, B. Aires, Ediciones Ciudad Argentina, 1997, 31-34,
} 
En la línea argumental que venimos desarrollando, la tipicidad de los delitos imputados o su antijuricidad, según sea el enfoque dogmático penal que se plantee, ocurre al descontextualizar histórica y culturalmente los hechos. Ahora bien, en el caso de 2001 no estaba vigente en Chile el Convenio 169 de la OIT, mientras en el de 2013 sí. Luego existiendo en ambos casos razones de justicia material, es evidente que en el segundo proceso descrito hay una errónea aplicación de la dogmática penal al desconocer los efectos del derecho fundamental a la identidad cultural en el sistema penal.

De igual forma, un supuesto de conducta legítima y o "atípica" (penalmente) ocurre con actividades tradicionales como la faena tradicional de animales para consumo de subsistencia respecto del delito de "beneficio clandestino"; o bien, también existe un actuar legítimo en los casos de la costumbre indígena de conservar, portar o usar armas de fuego con fines de subsistencia tradicional (caza y o resguardo de animales de crianza) y religiosas (armas de fuego usadas en ceremonias andinas y en rogativas mapuche) que se ha considerado constitutiva del delito de "porte ilegal de armas"

Asimismo, en otros casos latinoamericanos se imputó a autoridades ancestrales o dirigentes indígenas por acciones de naturaleza jurisdiccional, realizadas en representación de una colectividad indígena, que colisionaron con dispositivos constitucionales, afectando su derecho a conservar sus costumbres e instituciones propias (art. 8.2 del Conv. 169). Por ejemplo, aunque no alcanzó a la imputación penal de sus autoridades- un "Joven Paez" (Pueblo Paez en Cúcuta, Colombia) que fue sometido a "reclusión reservada" por autoridades indígenas de su pueblo, tras admitir - a instancias de su madre- el robo de unas gallinas. No hubo una sanción en sentido punitivo estricto, sino un tipo de medida correctiva y cautelar, aplicada al infractor ante su riesgo de muerte a manos de otros miembros de la comunidad, porque el joven podía ser asesinado en respuesta a su grave transgresión al valor de la "honradez" trató de una solución jurisdiccional indígena que recogió la medida tradicional y correctiva del encierro "hasta que cambie", bajo un especial fin de protección del mismo sujeto, al "reservar" u ocultar su lugar de reclusión, para la cautela de un bien de mayor jerarquía, la vida del joven ladrón. Ante la negativa de las autoridades indígenas de informar el lugar de reclusión, la madre del joven recurrió a diversas autoridades judiciales estatales para conocer el paradero de su hijo. Finalmente, la Corte Constitucional de Colombia acogió el reclamo y ordenó informar el paradero del joven ${ }^{99}$, fundada en las garantías constitucionales en materia de libertad preponderantes sobre la práctica indígena de la "reclusión reservada". Sin embargo, con el tiempo, como los paeces ya sabían que no podían matar a un ladrón en razón de la protección legal de la vida, los sectores más desconformes de la comunidad informaron a las FARC (atendido su control fáctico local) para que se hicieran cargo del joven ladrón. Ante ello, la madre suplicaba a las autoridades tradicionales del Pueblo Paez para que "guarden nuevamente a su hijo y lo mantengan escondido" ". De esta forma, la descontextualización del proceso y las decisiones judiciales que descartaron la solución de la jurisdicción indígena, por estimar que vulneraba los estándares constitucionales del debido proceso, terminaron dejando al infractor en situación de amplia vulnerabilidad.

97 TOP Arica, RIT 138-2015.

98 Sánchez Botero, 2006, op. cit., 186

99 TC Colombia, Sentencia de Tutela 1127 de 2001.

100 Sánchez Botero, 2006, op. cit., 183-215. 
También se cuestionó la potestad jurisdiccional indígena en el caso de la Comunidad "Tres Islas (Madre de Dios)" del Perú. La Fiscalía imputó de extorción a autoridades indígenas de la Comunidad por "querer controlar el ingreso a terceros en su territorio" amparados en el Convenio 169 de la OIT (arts. 8 y 18). Señala Yrigoyen que fueron perseguidos penalmente por "algo que no es delito", por el ejercicio de funciones jurisdiccionales constitucionales (art. 149) ${ }^{101}$. En el mismo sentido, en el Caso de la Comunidad "La Cocha" (Ecuador, 2010), el Ministerio Público abrió instrucción penal contra siete autoridades tradicionales de esta comunidad por el delito de secuestro y se decretó su prisión preventiva, por haber, a su vez, iniciado una causa penal (indígena) por el delito de homicidio contra cinco integrantes de la comunidad. La Fiscalía estimaba que la justicia indígena era incompetente en causas penales. Tanto autoridades indígenas, como los indígenas sancionados, recurrieron a la Corte Constitucional del Ecuador ${ }^{102}$. La Corte resolvió en favor de ellos considerando legítimas las decisiones de la justicia indígena comunitaria La Cocha, amparadas por la propia Constitución de 2008 (art. 171) ${ }^{103}$.

Sintetizando, podemos observar que aunque la jurisprudencia muestra un avance, especialmente en Chile se sigue evidenciando el problema de un insuficiente ejercicio efectivo del derecho a la identidad cultural y que, respecto a su aplicación en el proceso penal y a las categorías de la dogmática penal, se observa aún "una errónea y no neutral" aplicación de ellas, dejando los sistemas de justicia indígena con frecuencia bajo subordinación del Derecho estatal $^{104}$.

Con todo, el sostenido esfuerzo por el ejercicio del derecho fundamental a la identidad cultural, visualiza caminos posibles de fisura en el paradigma penal hegemónico que puede elevar los estándares de Justicia en sentido intercultural. En esta línea, los fallos, bajo condiciones interculturales, debieran conectar, transitar, progresivamente, desde el marco cognitivo penal del Derecho positivo, hasta los contextos de los respectivos sistemas culturales indígenas de referencia de las personas indígenas imputadas por el sistema punitivo del Estado. Luego, bajo el enfoque estudiado, el desafío emancipatorio del derecho fundamental a la identidad cultural de los pueblos indígenas consiste en una recomprensión del Derecho Penal que supone, a su vez, articular la decisión judicial con los presupuestos culturales de la cosmovisión indígena que están fuera del marco cognitivo del juez. Así, el reconocimiento del derecho fundamental a la identidad cultural impone la validación estatal del contexto cultural de los pueblos indígenas.

101 El Tribunal Constitucional del Perú acogió la reclamación indígena y actualmente lo conoce la CIDH. Yrigoyen, Raquel, Litigio estratégico en derechos indígenas. La experiencia de la Comunidad nativa 'Tres Islas' Madre de Dios Perú. Lima, IIDS, 2013, 125-131.

${ }^{102}$ Llásag, Raúl, "Justicia indígena ¿delito o construcción de la plurinacionalidad?: La Cocha”, en B. de S. Santos, A. Grijalva (Editores), Justicia Indígena, plurinacionalidad e Interculturalidad en Ecuador, Quito, Abya Yala F. R. Luxemburg, 2012, 344-345.

103 Corte Constitucional del Ecuador, Caso No $0731-10-E p$.

104 Aquí recogemos algunas reflexiones del trabajo colectivo, Faundes, et. al, "Reconocimiento del derecho fundamental a la identidad cultural en la defensa penal de imputados indígenas, a la luz del Convenio $\mathrm{N}^{\circ} 169$ de la OIT", ponencia IV Jornadas de Derecho Penal de la Universidad Austral de Chile, 2016. La idea de "una errónea y no neutral" aplicación de las categorías penales es de Sebastián García Ábalos. 


\section{Conclusión}

La emergencia progresiva del derecho fundamental y de naturaleza colectiva a la identidad cultural de los pueblos indígenas, como base de la sobrevivencia de estos pueblos, altera toda la hermenéutica en torno a la protección de este derecho, especialmente frente al sistema penal del Estado. Se trata de un nuevo paradigma que se instala dentro de la legislación y jurisdicción del Estado. Este giro normativo abre puentes de articulación entre los sistemas de justicia estatal e indígena/as, donde la administración de justicia estatal, desde la concepción del Estado de Derecho, ha sido y en buena medida sigue siendo el sistema de justicia hegemónico, pero empieza a ser "fracturado".

En el marco indicado, el examen penal de la conducta de los imputados miembros de los pueblos indígenas, por parte de los tribunales de justicia estatal, se debe encuadrar dentro del contexto cultural, de los referentes de sentido, propios del contexto histórico, social y cultural en que se sitúa aquella acción o conducta penalmente relevante (para el Estado), superando los parámetros unidimensionales clásicos de la dogmática penal asociada al derecho imperante. Por lo tanto, la decisión judicial que no considere de manera sustancial el sistema cultural propio de las culturas indígenas en que ocurrió la acción sometida a examen jurisdiccional, no podrá ser un fallo "justo" porque se "escribirá" y "dirá" desde uno solo de esos referentes cognitivos, culturales y normativos: el del Estado nación.

Un cambio de esta naturaleza y, por lo tanto, una ponderación penal esencialmente distinta, debiera arrojar un juicio de reproche (o no) diferente y, en especial, permitiría validar aquellos sistemas normativos indígenas que se mantienen en el silencio que impone el ejercicio de la violencia "legítima" por parte del Estado nación, con su proceso penal y la consiguiente sanción penal. En este sentido, el derecho fundamental a la identidad cultural de los pueblos indígenas constituye el fundamento de una defensa penal "cultural" que abre un marco nuevo y relevante de emancipación normativa, hoy pionero en la defensa penal y de potenciales efectos expansivos a otras materias judiciales donde puedan ventilarse conflictos que tengan un efecto sobre la cultura y cosmovisión de los pueblos indígenas, los cuales son de recurrente frecuencia, como la jurisdicción de familia y la ambiental.

El ejercicio de re-comprender las conductas desde la perspectiva histórica, social y cultural en que han ocurrido, sobre la base de relaciones interculturales, requiere de una mediación experta y pertinente culturalmente, como lo viene resolviendo de manera progresiva el peritaje antropológico desde una epistemología que también requiere emanciparse. Este instrumento científico social aplicado y normativo ha permitido establecer nexos cognitivos, jurídicos y axiológicos que dan sentido a la Justicia en el marco de la administración de justicia hegemónica. Luego, al encuadrar la pericia antropológica dentro del alcance del derecho fundamental a la identidad cultural, giramos el mero sentido instrumental de este medio de prueba. De esta forma, lo que podemos plantear como el derecho emergente al peritaje antropológico ahora se pasa a ubicar en el centro de los derechos de los pueblos indígenas, considerándolo un mecanismo articulador y supuesto necesario del respeto de las culturas indígenas.

En la medida que se de efectividad al derecho fundamental a la identidad cultural de los pueblos indígenas mediante un examen jurisdiccional que necesariamente considere el contexto histórico, social y cultural de quienes son sometidos al sistema judicial, puede ocurrir una 
fractura conceptual y normativa a la noción de Estado de Derecho. Mientras más sumemos al ejercicio del derecho, más dada será su justificación, lo que nos permitirá empezar a pensar la posibilidad de "Justicia intercultural", entendida solo como un horizonte posible bajo las condiciones aún hegemónicas del Derecho positivo frente a las formas de "justicia indígena" actualmente resistentes en Chile y América Latina.

\section{Bibliografía}

\section{Fuentes impresas:}

Aylwin, José, Meza-Lopehandía, Matías, YAÑEZ, Nancy, Los pueblos indígenas y el derecho, Santiago, LOM, Observatorio Ciudadano, 2013.

Barrientos Pardo, Ignacio, "Licitud del porte y uso de la hoja de coca", Política Criminal, N 5, 2008, A 4-5, 1-30, 2008.

Becerra, Nicolás, Derecho penal y Diversidad Cultural. La cuestión Indígena, B. Aires, Ediciones Ciudad Argentina, 1997.

Carmona, Cristobal.

"Entrando al círculo: la antropología jurídica y la posibilidad de justicia intercultural", en, M. Castro (Ed.), Los Puentes entre la Antropología y el Derecho. Orientaciones desde la Antropología Jurídica, Santiago, PRANJU U.Ch, 379-404, 2014, 388-393.

"Hacia una comprensión "trágica" de los conflictos multiculturales: acuerdos reparatorios, VIF y derecho propio indígena", Revista Cbilena de Derecho, V. 42, N 3, 975-1001, 2015.

Claros, Luis y Viaña, Jorge, "La interculturalidad como lucha contrahegemónica. Fundamentos no relativistas para una crítica de la de la cultura", en J. Viaña, L. Claros; J. Estermann; R. FornetBetancourt..., Interculturalidad crítica y descolonización Fundamentos para el debate, 81-147, La Paz, Convenio Andrés Bello.

Cortina, Adela, Justicia cordial, Valencia, Trotta, 2010.

Cury, Enrique, Derecho Penal. Parte General. Santiago: Ed. U. Católica de Chile, 2005

De Maglie, Cristina. Los delitos culturalmente motivados ideologias y modelos penales, Madrid, Marcial Pons, 2012, 136.Del Carpio Rodríguez, Columba, Pluralismo jurídico, derecho bumano a la identidad cultural y globalización, Pamplona: CIVITAS, Thomson Reuters, 2014.

Del Real, Alberto, El derecho a la identidad cultural, Pamplona, Ed. Aranzadi S.A., 2014.

Durán, Teresa, Berho, Marcelo, Carrasco, Noelia, Mora, Héctor, Antropología desde el sur. Obras escogidas de Teresa Durán, Temuco, Ed. U.C. Temuco.

Faundes, Juan Jorge.

"Honneth y la demanda por reconocimiento intercultural de los pueblos indígenas", Perfiles Latinoamericanos, $\mathrm{N}^{\circ}$ 49, junio, 303-323, $2017 \mathrm{a}$.

"Derechos humanos y el reconocimiento de la identidad cultural de los pueblos indígenas en América Latina, en la perspectiva crítica del descentramiento intercultural", en Jorge Olvera, Julio Olvera y A. L. Guerrero (coords.), Los pueblos originarios en los debates actuales de los derechos bumanos, México, UAEM, Porrúa, 2017b.

"Recomprensión intercultural de los derechos humanos. Apuntes para el reconocimiento de los pueblos indígenas en América Latina", Justiça do Direito, v.29, Nº1, 2015, 108-130.

"Derechos fundamentales y derechos humanos", en, M. Álvarez y R. Cippitani (coords.), Diccionario Analítico de Derechos Humanos e Integración Jurídica. Roma-Perugia-Mexico: ISEG, 2013,

Fornet-Betancourt, Raúl. 
Juan Jorge Faundes, Derecho fundamental a la identidad cultural de los pueblos indígenas: un nuevo paradigma en la defensa penal indígena en Chile frente al Estado de Derecho hegemónico, Izquierdas, 45, febrero 2019:51-78

La Filosofía Intercultural y la dinámica del reconocimiento, Temuco, Ediciones Universidad Católica de Temuco, 2011.

"Tareas y propuestas de la filosofía intercultural, Sobre el concepto de identidad", Concordia, Reihe Monographien Band 49, 2009a, 47-54.

"La pluralidad de conocimientos en el diálogo intercultural", en D. Mora (ed.), La pluralidad de conocimientos en el diálogo intercultural, La Paz, C. A. Bello, 9-20, 2009b.

Forst, Rainer, Justificación y crítica. Perspectivas de una teoría crítica de la política, B. Aires, kats Editores, 2014.

Grimson, Alejandro.

"Los Límites de la cultura. Crítica de las teorías de la identidad”. B. Aires, S. XXI, 2011.

"Culture and identity: two different notions", en Social Identities, vol. 16 N¹, Jan. 2010

Honneth, Axel.

La lucha por el reconocimiento. Por una gramática moral de los conflictos. Barcelona: Crítica, 1997.

"Redistribución como reconocimiento: Respuesta a Nancy Fraser", en N. Fraser, A. Honneth, ¿Redistribución o reconocimiento? Un debate político-filosófico, 89-148, Madrid, Morata.

Kalinsky, Beatriz, Justicia, Cultura y Derecho Penal, B. Aires, Ad-Hoc S.R.L., 2000.

Kymlicka, Will, Multicultural Citizenship, Oxford, Oxford University Press, 1995.

Kusch, R. (1962). América profunda. B. Aires: Hachette.

Llásag, Raúl, "Justicia indígena ¿delito o construcción de la plurinacionalidad?: La Cocha”, en B. de S. Santos, A. Grijalva (Eds.), Justicia Indigena, plurinacionalidad e Interculturalidad en Ecuador, Quito, Abya Yala F. R. Luxemburg, 2012, 321-372.

Lombraña, Andrea, Carrasco, Morita (Edts.), Experiencias de lectura insolente: abordajes empíricos en el campo jurídico, B. Aires, Antropofagia Editorial, 2018.

Mariman, Pablo, "Los mapuche antes de la conquista militar chileno-argentina", en P. Mariman, S.

Caniuqueo, S. Millalen, R. Levil, ij...Escucha, winka...!! Cuatro ensayos de historia nacional mapuche y un epílogo sobre el futuro, 53-127, Santiago, LOM, 2006.

Mouffe, Chantal, El Retorno de lo Politico. Comunidad, Cuidadania, Pluralismo y Democracia Radical, B. Aires, Paidós, 1999.

Preciado, Hugo, Interpretación de los derechos Humanos y los Derechos Fundamentales, Pamplona, Tomson Reuters ARANZANDI, 2016.

Ramírez, Silvina.

"Igualdad como Emancipación: Los Derechos Fundamentales de los Pueblos Indígenas", en Anuario Centro de Derechos Humanos, Santiago, Universidad de Chile, 2007.

Constitucionalismo y derechos de los pueblos indígenas, B. Aires, La Ley, 2013.

Rancière, Jack, El desacuerdo. Política y Filosofía, 1996.

Ruiz Chiriboga, Oswaldo, "El derecho a la identidad cultural de los pueblos indígenas y las minorías nacionales: una mirada desde el sistema interamericano", Revista Internacional de Derechos Humanos, Vol. N5, año 3, 2006, 43-69.

Salas, Ricardo, Ética Intercultural. (Re)lecturas del Pensamiento latinoamericano, Santiago, Ediciones UCSH, 2003.

Salas, Ricardo, Faundes, Juan Jorge, "Justicia e interculturalidad. Conflictos y desafíos jurídico-políticos en el Wallmapu (Chile)", en M. Ledesma (coord.), Justicia e Interculturalidad, análisis y pensamiento plural en América y Europa. Lima: Centro de Estudios Constitucionales - Tribunal Constitucional del Perú 2018, 693-737.

Sanchez Botero, Esther.

El peritaje antropológico, Justicia en clave cultural, Bogotá, GTZ, 2010.

Entre el Juez. Salomón y el Dios Sira. Decisiones interculturales e interés superior del niño, Bogotá, Universiteit van Amsterdam, UNICEF, 2006.

Sanchez Botero, Esther; Gómez, Herinaldy, El Peritaje Antropológico. Como Prueba Judicial, Bogotá, 
RELAJU, Instituto Colombiano de Antropología e Historia, 2008.

Santos, Boaventura de Sousa, Conocer desde el sur. Para una cultura política emancipatoria. Lima, U. de San Marcos, 2006.

Tapia, Luis, El estado de derecho como tirania, La Paz, CIDES, Autodeterminación, 2011.

Vergara, Jorge Ivan, Vergara Estévez, Jorge, Gundermann, Hans, "Tramas y laberintos: sociología e identidad cultural latinoamericana", Atenea, 2012, No 15, 13.

Villegas, Myrna, "Sistemas Sancionatorios indígenas y Derecho Penal ¿Subsiste el Az Mapu?”, Política Criminal, Vol. 9, N 17, 213-247, 2014.

Villegas, Myrna, Mella, Ed., Cuando la costumbre se convierte en ley. La cuestión penal y la pervivencia de los sistemas sancionatorios indígenas en Chile, Santiago, Lom, 2017.

Yrigoyen, Raquel.

"El horizonte del constitucionalismo pluralista: del multiculturalismo a la descolonización", en C. Rodríguez, El derecho en América Latina. Un mapa para el pensamiento jurídico del siglo XXI, B. Aires, S. XXI, 2011. 139-159

Litigio estratégico en derechos indigenas. La experiencia de la Comunidad nativa 'Tres Islas' Madre de Dios-Perú, Lima, IIDS, 2013.

\section{Documentos}

Defensoría Penal Pública (DPP).

Modelo de Defensa Penal Indígena, 2012.

$2^{\circ}$ Informe de jurisprudencia sobre defensa penal de imputados indígenas, 2013.

Faundes, Juan Jorge, Nahuelcheo, Pamela, García, Sebastián, "Reconocimiento del derecho fundamental a la identidad cultural en la defensa penal de imputados indígenas, a la luz del Convenio $\mathrm{N}^{\circ} 169$ de la OIT", ponencia en IV Jornadas de Derecho Penal de la Universidad Austral de Chile, Valdivia, 24 y 25 de noviembre de 2016.

Porma, Carolina, "El reconocimiento al derecho a la identidad cultural de los pueblos indígenas, en la jurisprudencia de los tribunales chilenos", Tesis para optar al grado de Magister en Derecho Público, Facultad de Derecho de la Universidad Autónoma de Temuco, Temuco, Proyecto Fondecyt $\mathrm{N}^{\circ}$ $11161079,2017$.

U.C. Temuco, Defensoría Penal Pública (DPP), "Modelo de Gestión del Peritaje Antropológico" (MoGPA), Proyecto Fondef-Idea Peritaje antropológico para la Defensa Penal en contextos de diversidad cultural, N ID14I 10379, 2017.

\section{Fuentes digitalizadas:}

Donoso, Sebastián, "Chile y el convenio 169 de la OIT: reflexiones sobre un desencuentro", Temas de la agenda pública, Pontificia Universidad Católica de Chile, Año 3, № 16, abril, 2008.

http://politicaspublicas.uc.cl/wp-content/uploads/2015/02/chile-y-el-convenio-169-de-la-oitreflexiones-sobre-un-desencuentro.pdf

Fornet-betancourt, Raúl, Supuestos filosóficos del diálogo intercultural, 1998. http://www.ensayistas.org/critica/teoria/fornet/

Melin, Miguel, Coliqueo, Patricio, Curihuinca, E., Royo, M., AZMAPU: Una aproximación al sistema normativo Mapuche desde el Rakizuam y el Derecho Propio, 2016 http://bibliotecadigital.indh.cl/bitstream/handle/123456789/984/azmapu.pdf?sequence=1

Nash, Claudio (Dir.), Lagos, Catalina, Nuñez, Constanza, Erradicación de la Violencia Contra las Mujeres en las Américas: Violencia contra mujeres indígenas en el marco de las relaciones familiares: Pautas para 
Juan Jorge Faundes, Derecho fundamental a la identidad cultural de los pueblos indígenas: un nuevo paradigma en la defensa penal indígena en Chile frente al Estado de Derecho hegemónico, Izquierdas, 45, febrero 2019:51-78

decidir la procedencia de acuerdos reparatorios. Santiago, Centro de Derechos Humanos, Universidad de Chile, 2013. http://www.biblio.dpp.cl/biblio/DataBank/8028.pdf

Nogueira, Humberto, "El bloque constitucional de derechos: La confluencia del derecho internacional y del derecho constitucional en el aseguramiento y garantía de los derechos fundamentales en América Latina. Trigésimo séptimas Jornadas de Derecho Público", 1997a.

http://www.jornadasderechopublico.ucv.cl/ponencias/El $\% 20$ bloque $\% 20$ constitucional $\% 20 \mathrm{de} \% 20$ derechos.pdf

Real Academia Española (RAE), Diccionario de la lengua española, 2018. http://dle.rae.es/?id=KDXnico

Ruiz, Juan Carlos, “Aproximación a los fundamentos constitucionales del peritaje antropológico”, en A. Guevara Gil, A. Verona y R. Vergara (eds.), El peritaje antropológico. Entre la reflexión y la práctica, Lima, CICAJ, 2015.

http://departamento.pucp.edu.pe/derecho/wp-content/uploads/2015/05/Libro-completoPERITAJE.pdf

Vittor, Luis, "El ejercicio de la justicia indígena", en Aylwin, J. y Tamburini, J., Convenio No 169 de la OIT. Los desafios de su implementación en América latina a 25 años de su aprobación, Coponhage, IWIGIA, 2014.

http://observatorioetnicocecoin.org.co/cecoin/index.php?option $=$ com content\&view $=$ article\&id 三488:convenio-169-de-la-oit-los-desafios-de-su-implementacion-en-america-latina-a-25-anos-de-suaprobacion\&catid $=17$ :documentos-de-interes-mainmenu-66\&Itemid $=66$

\section{Jurisprudencia nacional:}

“Alejandro Papic Dominguez con Comunidad Indígena Aymara Chuzmiza y Usmagama”, Corte Suprema, Rol 2840-2008, 25 nov. 2009.

"Codelco Chile División Chuquicamata con Dirección Regional y Nacional de Aguas", C.S., Rol 14.003-13, 15 may. 2014.

“Comp. Minera Cerro Colorado con Fisco de Chile", C.S., Rol 6.628-2015, 4 may. 2016.

"Comunidad Indígena Antu Lafquen de Huentetique contra Comision Regional del Medio Ambiente Región de los Lagos", C.S., Rol 10.090-2011, sentencia 22 marzo de 2012.

"Curin Tromo Celmira c/Bosques Arauco S.A", C.A.Temuco, Rol 1.865-2008, 6 ene. 2009.

"Herminia Toroco Herrera y Amelia Mamani Charcas con Sociedad Inversiones e Inmobiliaria Villa Nueva S.A.”, C.S., Rol 3.010-2013, 26 sep. 2013.

“José Patricio Maripil Porteño, Miguel a. Porteño Naupa, Sebastián M. Porteño Naupa, Carlos F. Curriao Campos, José S. Porteño Naupa, Juan B. Huenupe Pavian, Mario Queupil Poblete, Félix Gallina Gallina, José H. Maripil Maripil, Jorge cabezas", C.S., Rol No 2683-10, 26 ene. 2012. J.L. Santa Bárbara Rol N 2.683-10

"Linconao Huircapan Francisca contra Sociedad Palermo LTDA.”, C.A. Temuco, Rol 1773-2008, 16 sep. 2009. C.S., Rol 7287-2009, 30 nov. 2009.

"Ñanculef Huaiquinao, Ruben con Nanculef Marin, Santiago", C.A. Temuco, Rol No 635-2012, 8 jul. 2011.

“Maria Isabel Jamerne Jamerne Contra Marta Angelina Colinanco Huechulef', J.G.Villarrica, RUC 1010033388-6, RIT 1494-2010, 9 feb. 2013; C.A.Temuco, Rol 130-2013, 1 abr. 2013; C.S., Rol 21451316, 16 may. 2013.

“Min. Público c/ Jorge Huenchullan C.”, C.A. Temuco, Rol RPP-388-2012, 4 jun. 2012.

“Min. Público Local”, C.S., Rol 10.635-2011, 4 enero 2012.

“Min. Público c/ Luis A. Marileo Ll.”, C.A. Temuco, Rol 499-2012, 17 jul. 2012.

“Min. Público c/ Ángel H. Velázquez Z.”, T.O.P. Arica, RUC 1410018700-1, RIT 27-2015, 2 mar. 2015. 
“Min. Público Arica c/ Juan C. Sánchez S.” T.O.P. Arica, RIT 138-2015, 18 may. 2015.

“Min. Público c/ Pedro S. Huaquiman”, T.O.P. Temuco, RIT 49-2006, 28 jun. 2006.

Rendel Augant Ingeborg con Comunidad Indígena José Gineo Nanco”, CS Rol 7.655-2008, C.S., 29

sep. 2010.

“Torres con Pérez”, JL Loncoche, 1: Causa Rol N C-374-2014, CS Rol N 45763-2017.

Tribunal Constitucional, Rol 2387-2012, 23 enero de 2013.

Tribunal Constitucional, Rol 2552-2013, 24 diciembre de 2014.

Tribunal Constitucional, Rol 309-2000, 4 agosto de 2000.

“Virginia Mollo M. con Ceferino Morales H.”, J.A. Arica, RIT 648-2013, de 4 dic. 2013.

"Contra de miembros de la comunidad indígena Domingo Trangol, por presuntos delitos de usurpación, daños calificados, robo, exacción ilegal y asociación ilícita". J.G. Victoria, RUC 231-7, 2001.

\section{Jurisprudencia internacional y comparada:}

Corte Constitucional de Colombia, Sentencia T-1127/01.

Corte Constitucional de Colombia, Sentencia T-778/05.

Corte Constitucional del Ecuador, Caso No 0731-10-Ep, 30 jul. de 2014, No 113-14-Sep.

Cte.I.D.H, "Caso de Pueblo Indigena Kichwa de Sarayaku versus Ecuador", 27 jun. 2012.

Cte.I.D.H., "Caso Comunidad Sawhoyamaxa contra el estado de Paraguay", 29 mar. 2006.

Cte.I.D.H, "Caso Pueblo indígena Xucuru y sus miembros vs. Brasil”, 5 feb. 2018. 